\title{
Investigation of the Effects of Environmental Fatigue on the Mechanical Properties of GFRP Composite Constituents Using Nanoindentation
}

\author{
H. Gonabadi ${ }^{1}$ - A. Oila ${ }^{1} \cdot$ A. Yadav ${ }^{1} \cdot$ S. Bull ${ }^{1}$
}

Received: 17 May 2021 / Accepted: 7 November 2021 / Published online: 29 November 2021

(c) The Author(s) 2021

\begin{abstract}
Background Fatigue failure criteria for fibre reinforced polymer composites used in the design of marine structures are based on the micromechanical behaviour (e.g. stiffness properties) of their constituents. In the literature, there is a lack of information regarding the stiffness degradation of fibres, polymer matrix and fibre/matrix interface regions affected by environmental fatigue.

Objective The aim of present study is to characterize the stiffness properties of composite constituents using the nanoindentation technique when fatigue failure of composites is due to the combined effect of sea water exposure and cyclic mechanical loads.

Methods In the present study, the nanoindentation technique was used to characterize the stiffness properties of composite constituents where the effects of neighbouring phases, material pile up and viscoplasticity properties of the polymer matrix are corrected by finite element simulation.

Results The use of finite element simulation in conjunction with nanoindentation test data, results in more accurate estimation of projected indented area which is required for measuring the properties of composite constituents. In addition, finite element simulation provides a greater understanding of the stress transfer between composite constituents during the nanoindentation process.

Conclusions Results of nanoindentation testing on the composite microstructure of environmentally fatigue failed composite test coupons establish a strong link to the stiffness degradation of the fiber/matrix interface regions, verifying the degradation of composite constituents identified by scanning electron microscopy (SEM) and energy dispersive X-ray spectroscopy (EDX) analysis.
\end{abstract}

Keywords Polymer Composites $\cdot$ Environmental Fatigue $\cdot$ Nano indentation $\cdot$ Atomic Force Microscopy $\cdot$ Stiffness Degradation · Finite Element Modelling

\section{Introduction}

In recent years, the use of composites with glass or carbon fibres embedded in a polymer matrix for the load bearing marine structures has significantly increased. The demand

H. Gonabadi

A. Oila

adrian.oila@newcastle.ac.uk

S. Bull

steve.bull@newcastle.ac.uk

1 School of Engineering, Newcastle University, Newcastle upon Tyne NE1 7RU, UK for using a polymer matrix composite necessitates defining failure criteria as well as understanding the mechanical behaviour under various types of loading $[1,2]$. Most of the failure criteria for fibre reinforced polymer (FRP) composites are based on the stress-strain response under macro-scale testing as opposed to the criteria based on micromechanical behaviour of in situ composite constituents. As a result, there is a missing link between the damage and failure modes at the micro and macro scale levels. This can be addressed by analysing the response of composite constituents and their interfaces under different loading conditions which requires examination of the microscopic failure modes. Micromechanical Finite Element (FE) simulation can be used for the stress and damage analysis of composite constituents and 
also to analyse the effect of composite constituent's properties on its larger scale behaviour, however, accurate properties of composite constituents need to be obtained as the input data. Studies [3-7] have shown that the nanoindentation technique is a powerful tool to determine the local mechanical properties of composite constituents with high resolution from the calculated force-displacement curves and therefore it can provide input parameters for FE simulation of composite microstructure, consequently creating a link between micro-scale and macro-scale. Although these studies have used numerical and/or experimental nanoindentation analysis for the characterization of the composite constituents, they assume that the polymer matrix exhibits elastic-plastic properties [3,5-10], ignoring the effect of viscoelasticity and creep (viscoplasticity). The other challenge regarding the prediction of deformation mechanisms and damage accumulation in polymer composite constituents and their effects on the macroscopic structure using finite element approaches [11-13] is that it is widely assumed that the properties of composite constituents are the same as to those in bulk form. However, the high-temperature curing process which is linked with composite manufacture can result in the thermal, mechanical and chemical processes occurring during the consolidation of the composite constituent phases. For example, the interaction of the matrix phase (i.e. epoxy resin) with fibre coupling agents, surface treatments and sizing can lead to mechanical properties and residual stress that are different from those measured using bulk samples, with substantial differences existing in matrix phases near the F/M interfaces [5, 14].

Because of the complex and multiple failure modes of polymer composites, predicting the failure of large composite structures based on the micromechanical behaviour of composite constituents is challenging. Although the micromechanical behaviour of composite constituents can be investigated using nanoindentation techniques, the main problem is the analysis method to characterize the viscoelasticity and creep behaviour of polymer matrix composites by the nanoindentation method, which is still not resolved. The analysis procedure of nanoindentation to determine the elastic modulus and hardness is based on the Oliver and Pharr method [15] where the assumption is that the material has elastic-plastic properties and does not show viscoelasticity or viscoplastcity. Therefore, the method is not applicable to time-dependent materials such as the polymer matrix where creep or relaxation is an issue. In the present work, to address this problem, a methodology based on a combined method of FEM and experimental nanoindentation is developed where the effects of viscoplastic properties of the polymer matrix, fibre constraint and material pile up are considered resulting in a more accurate measurement method to assess the micromechanical behaviour of in-situ composite constituents.
Another issue when characterizing the micromechanical properties of materials with elastic/plastic behaviour using nano indentation technique is that the material around the contact area is pushed upwards or downwards against the indenter's tip to form pile-ups or sink-ins on the edges (Fig. 1), affecting the calculation of contact area. In pure elastic contact, the material always sinks-in whereas in the case of elastic/plastic response it may either sink-in or pileup. Since it has an important effect on the measurement of contact area, the mechanical properties such as hardness and elastic modulus can be different [16]. Pile-ups normally increase the effective contact area. Therefore, if the load is divided by an increased area of contact, the hardness will decrease when compared with that for the area in the absence of pile-up. The influence of pile-up around various indenters for the evaluation of hardness and elastic modulus has been studied by a number of researchers [17-19]. In general when pile-up occurs, the magnitude of hardness and modulus calculated by the Oliver and Pharr method are too high as the method is based on the contact area in the plane of the original surface, rather than the true contact area. Therefore, significant error can be encountered using Oliver-Phar method when applied to elastic/ plastic materials [15]. According to Bolshakov and Pharr [20] when the ratio of final depth to the maximum depth $\left(\mathrm{h}_{\mathrm{f}} / \mathrm{h}_{\max }\right)$, which can be measured experimentally and correlates with the materials parameters measurable from the indentation load-displacement data, exceeds the value of 0.7 , pile-up occurs.

The majority of the research in nanoindentation of polymer composite materials and their constituents has been done since the early 2000s. It has been shown that developments in experimental nanoindentation, numerical simulation of nanoindentation and combined experimental/ numerical Nano indentation techniques are useful in the characterization of polymer matrix materials, fibres, particles and other constituents in particular when the effects of

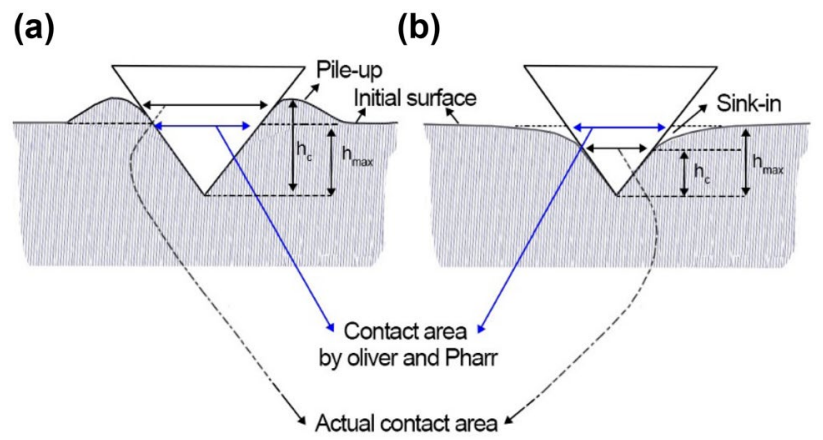

Fig. 1 Schematic of contact profile developed during Nano-indentation showing (a) pile-up and (b) sink-in which results in overestimation or underestimation of the indentation modulus measured by Oliver and Pharr method. $h_{\max }$ is the indentation depth and $h_{c}$ is the contact depth 


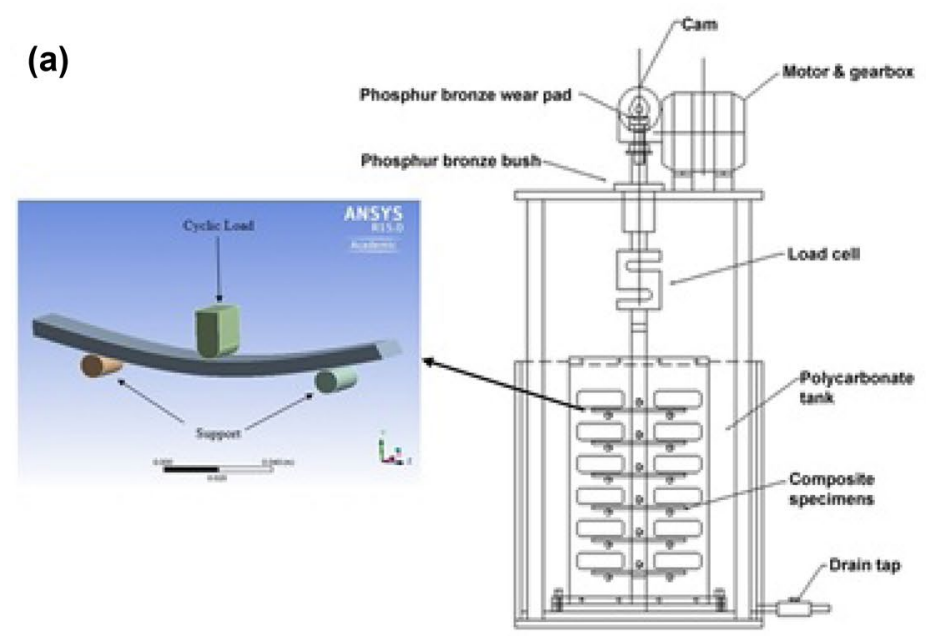

(b)

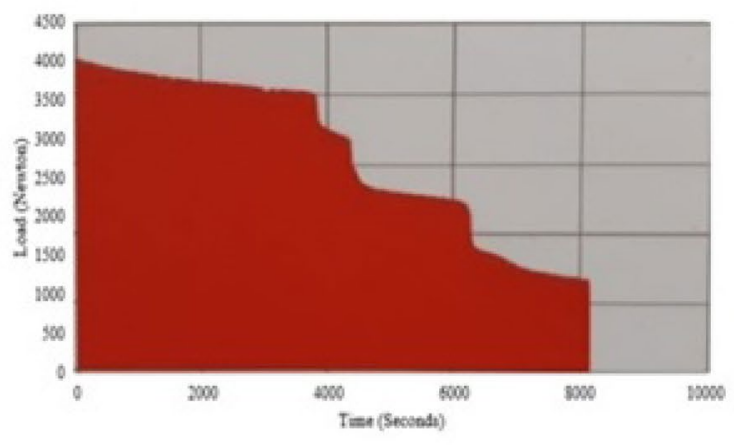

Fig. 2 (a), 3 PB configuration of fatigue test specimen under cyclic loads and exploded-view schematic of 3 PB fatigue rig. (b) Load versus time during the fatigue test of multiple specimens

fibre constraint, viscoelastic and dynamic mechanical properties of the constituents are considered [21]. The effect of fibre constraint and the evolution from bulk to in-situ matrix properties has been characterised using nanoindentation experiments and it was shown that the in-situ matrix modulus increases with decreasing matrix pocket size, and is generally larger than that of the bulk matrix [5, 22]. In another study [7], a thorough investigation of the fibre constraint on the Nano indentation response of the matrix region of fibrous composites has been carried out using finite element methods and was shown that using the Oliver and Pharr method to determine the contact area can underestimate the contact area due to the occurrence of pile-up, which is induced by the constraining fibres. The difference between the elastic modulus determined using tensile testing of polymers and those determined using Nano indentation given the effect of pile-up, viscoelasticity and hydrostatic stress on the indentation modulus of an epoxy matrix material were investigated and it has been shown that nanoindentation overestimates the elastic modulus significantly mainly due to the effect of viscoelasticity and hydrostatic stress [23].

Accounting for the long term environmentally affected fatigue degradation of FRP is an important element in the multi-scale modelling of composite components in marine applications but it requires reliable test data from experiments. The experimental approach to account for the combined effects of sea water and cyclic loads based on fatigue testing of composite test coupons in sea water can provide a realistic estimation of the long-term behaviour but still requires understanding the micromechanical behaviour of the composite constituents. Understanding this at the nano scale can provide insights for improving the performance of the composite on the macro-scale resulting in an optimal and safer design of composite structures.
Glass fibre reinforced polymer (GFRP) composites are frequently used in load bearing marine structures (e.g. tidal turbine blades) where the combined effect of sea water exposure and cyclic mechanical loads limit the fatigue life [24]. In this study, although, macro-scale failure of composite tidal turbine blades was predicted using a combined methodology of Blade Element Momentum and Finite Element Modelling (BEM-FEM), there is a missing link between macro-scale failure of composite blades and micro-scale failure of composite constituents. In this study [24], it was found that during the fatigue test, sea water penetrates into the network of resin cracks and de-bonded fibres, accelerating fibre and fibre/matrix interface degradation. In addition, similar findings in terms of failure modes during the environmental fatigue testing of composites have been reported in the literature where the impact of salt water on

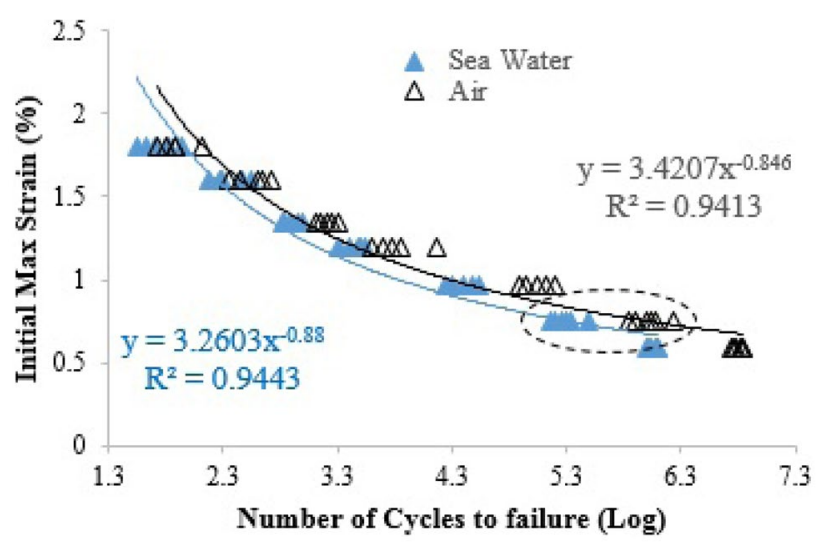

Fig. 3 Strain -Number of cycles to failure plots of GFRP composites under different strain levels in wet and dry conditions. The curve has been generated in terms of strain due to the creeping peak strain values during the constant strain amplitude fatigue tests 
Fig. 4 (a) Tensile stress-strain curves of epoxy resin at different strain rate and $(\mathbf{b})$ variation of strain versus time (a)

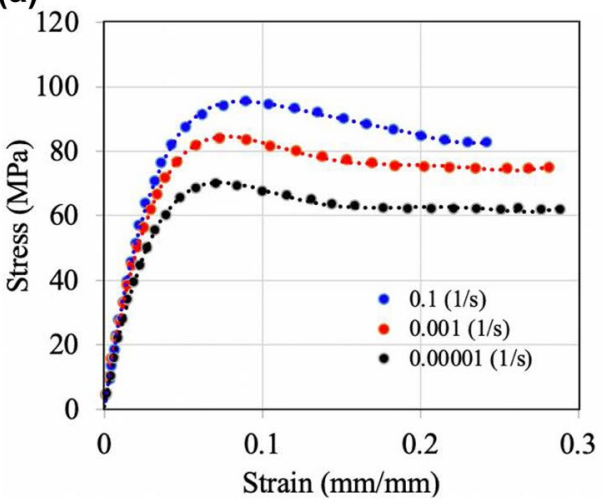

(b)

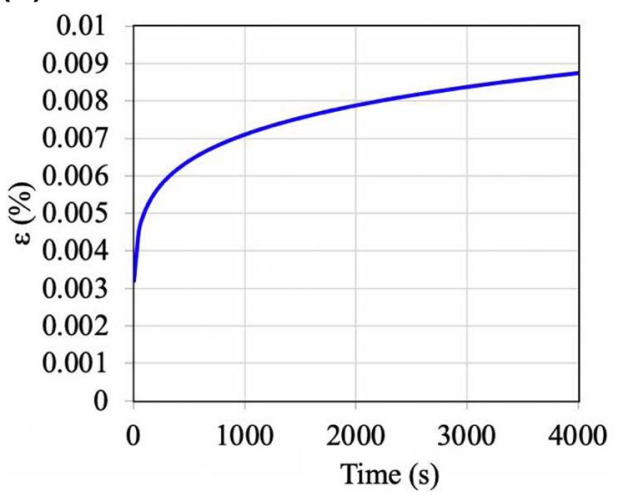

the fatigue behaviour of a glass fibre reinforced polymer in terms of moisture and water absorption has been investigated experimentally [25]. Therefore, apart from matrix cracking, interfacial de-bonding between fibres and matrix, delamination and fibre fracture, failure modes such as degradation of the fibre, polymer matrix and fibre/matrix interface properties are controlling factors in the environmentally-affected fatigue testing of GFRP. From previous studies [24, 26], macroscopic failure and stiffness degradation of composite materials used in the design of tidal turbine blades were investigated during the environmental fatigue testing. In these studies, although SEM integrated with EDX was used to identify the above failure modes, the aim of present work is to use nanoindentation technique to verify the degradation of F/M interface properties, finally contributing to understand the link between macro-scale and micro-scale behaviour of environmentally-affected composite structures.

\section{Methodology}

In this study, nanoindentation assessment of the polymeric parts of a composite involves strain rate dependent properties (viscoplasticity) as well as the effect of pile up and the mechanical constraining effect of fibres. Therefore, a combined method of FEM and nanoindentation testing was used to develop an analysis procedure in order to characterize the micromechanical behaviour of composite constituents.

Table 1 Viscoplasticity models and calculated parameters of fresh samples of epoxy resin used in FE model

\begin{tabular}{|c|c|c|c|c|}
\hline \multirow{3}{*}{$\begin{array}{l}\text { Model } \\
\text { Perzyna } \\
\dot{\varepsilon}_{p l}=\gamma\left(\frac{\sigma}{\sigma_{0}}-1\right)^{1 / m}\end{array}$} & \multicolumn{4}{|c|}{ Parameters } \\
\hline & $\sigma_{0}(\mathrm{MPa})$ & $m$ & $\gamma$ & \\
\hline & 70 & 0.1505 & 218.62 & \\
\hline $\begin{array}{l}\text { Modified Time Hardening } \\
\qquad C_{1} \times \sigma^{c_{2} \times t^{c_{3}+1}}\left(\exp \left(-\frac{c_{4}}{T}\right)\right)\end{array}$ & $C_{1}$ & $C_{2}$ & $C_{3}$ & $C_{4}$ \\
\hline$C_{3}+1$ & $3.78 \mathrm{e}-5$ & 1 & -0.85 & 0 \\
\hline
\end{tabular}

Initially, the above method is implemented to account for the effect of viscoplasticity of the bulk (unreinforced) polymer matrix. To do this, viscoplasticity parameters calculated using tensile testing (at various strain rates) and creep testing on bulk epoxy resin samples are used in an FE model of nanoindentation resulting in predictions for the validation of experimentally determined load displacement data. To correct the effect of pile up, rather than estimating the projected contact area using Oliver and Pharr method, the FE calculated contact area was used by identifying the last contact point at maximum load in the FE mesh, resulting in a more accurate measurement of elastic modulus of the epoxy resin. Next, using the validated viscoplasticity parameters, an FE model of nanoindentation on different locations in the composite microstructure was developed and finally numerically calculated load displacement curves were compared with the experimental ones resulting in the more complete validation of the FE nanoindentation model. The FE model can help to understand how the mechanical response of the composite constituents is affected by the stress distribution during the nano indentation process. In particular, it shows how the matrix properties in nanoindentation are affected by the stress transfer at the fibre interface which is due to the constraining effect of surrounded glass fibres. The effect of pile up was also corrected by FE calculated contact area when measuring the contact modulus of in situ constituents and the F/M interface. Finally, nanoindentation experiments were conducted on GFRP composite test coupons subjected to high cycle fatigue testing in order to determine how the

Table 2 Mechanical properties of composite constituents used for the FE model

\begin{tabular}{lll}
\hline Properties & Glass fibre (isotropic) & $\begin{array}{l}\text { Epoxy resin } \\
\text { (isotropic) }\end{array}$ \\
\hline$E(\mathrm{GPa})$ & 72 & 3.78 \\
$\nu$ & 0.21 & 0.35 \\
$G(\mathrm{GPa})$ & 29.75 & 1.48 \\
$U T S(\mathrm{MPa})$ & 3300 & 85 \\
\hline
\end{tabular}


mechanical properties of all composite constituents are affected by fatigue in sea water and air conditions. This has been done based on an inverse finite element approach where the obtained convergence between the numerical and experimental load-displacement curves resulted in the extraction of mechanical properties that are fed into the finite element model. It must be noted that the elastic modulus of composite constituents from either fatigue loaded test coupons in sea water and air or fresh composite test coupons have been calculated by averaging data from the 20 indentations using the Oliver and Pharr method and the mean value of modulus are reported in this study.

\section{Composite Manufacture and Fatigue Testing Rig}

Glass fibre composites, consisting of 16 plies of nonwoven glass fabric were made using the vacuum assisted resin transfer moulding (VARTM) technique at room temperature. Initially biaxial stitched glass fibre mat $\left[\left(0^{\circ}\right.\right.$ $\left.\left.290 \mathrm{~g} / \mathrm{m}^{2}, 90^{\circ}-290^{\mathrm{g}} / \mathrm{m}^{2}\right)\right]$ are stacked to create a symmet-ric cross ply $[0,90]_{s}$ laminate in a closed vacuum mould. Then resin system (i.e. epoxy resin based on Bisphenol A cured and cross-linked with an amine hardener) was intro-duced under vacuum, moving the air through the opening. Once the volume between reinforcing fibres are filled by the epoxy resin, curing occurs. Finally, GFRP laminate with the approximately $35 \%$ fibre volume frac tion was achieved and was cut into $15 \times 150 \mathrm{~mm}^{2}$ test coupons for the fatigue tests.

\section{Fatigue Testing}

Fatigue tests were performed in the three point bending (3 PB) mode detailed in $[24,26]$ at the loading frequency of
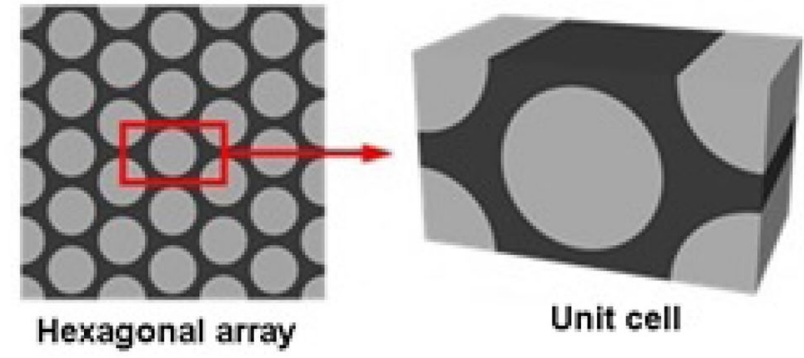

Unit cell

Fig. 5 Hexagonal arrays of glass fibres embedded in the epoxy resin system and the corresponding unit cell used for FE modelling

$1 \mathrm{~Hz}$ in two different environments, i.e. natural North Sea water from the Dove Marine Laboratory (3.5\% dissolved salts, predominantly $\mathrm{NaCl}(2.4 \%), \mathrm{MgSO}_{4}(0.5 \%)$ and $\mathrm{MgCl}_{2}$ $(0.3 \%)$ and laboratory air at room temperature $\left(20 \pm 2{ }^{\circ} \mathrm{C}\right.$. The specimens were cut from the composite panel made in the lab and a total of 60 samples were obtained; 30 samples were tested under fatigue loading while exposed to air, whilst the other 30 specimens were tested under fatigue loading while immersed in sea water with the same configuration at room temperature. $3 \mathrm{~PB}$ fatigue tests involved cycling specimens under constant deflection using a specially designed test machine (load cell of $25 \mathrm{KN}$ ) until failure. In order to avoid specimen motion, impact on the sample and the variation of the loaded point on test coupon during the fatigue test, the strain ratio was kept at $\mathrm{R}=\frac{\varepsilon_{\min }}{\varepsilon_{\max }}=0.1 R=\frac{\varepsilon_{\min }}{\varepsilon_{\max }}$. The configuration for the $3 \mathrm{~PB}$ fatigue test (Fig. 2(a)) was the same as used for quasi-static 3 PB test in terms of test coupon dimensions, geometry, span supports and loading roller positions. According to the standard test method of ES BN ISO13003 [27] for bending fatigue behaviour of composites, five coupons were tested at each of different strain levels between 50 and $90 \%$ of their (a)

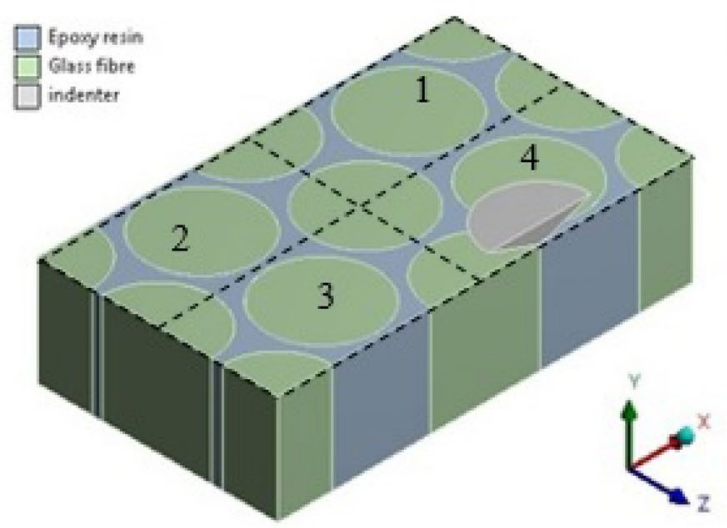

(b)

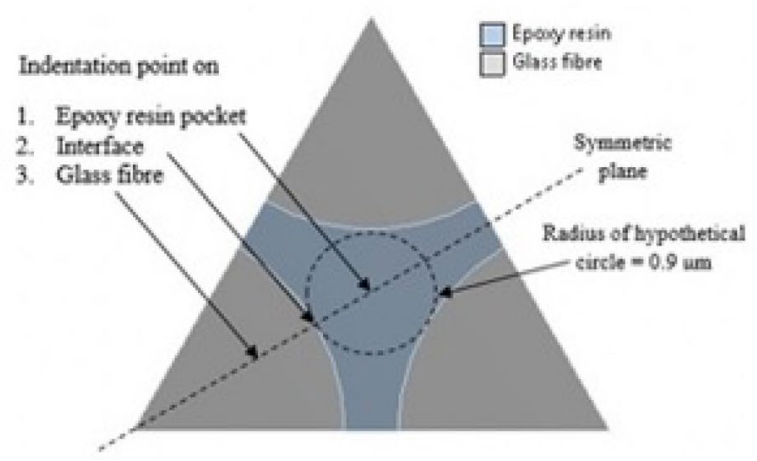

Fig. 6 Sketch of FE models of conical indentation, (a) 3D model of fibre-matrix composite, (b) Simplified view of the fibre packing arrangement around the indentation region on the epoxy resin, glass fibre and F/M interface 
Fig. 7 AFM image of a residual indentation print from an indentation carried out on the unreinforced epoxy resin, highlighting locations of line scans, (b) Line scans $\mathbf{A}, \mathbf{B}$ and $\mathbf{C}$ (a)

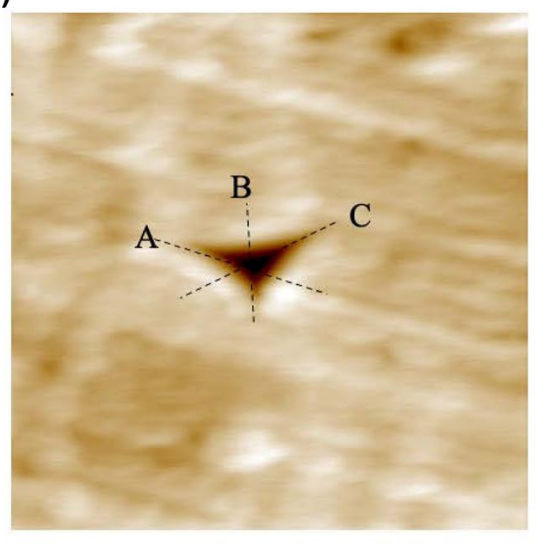

(b)

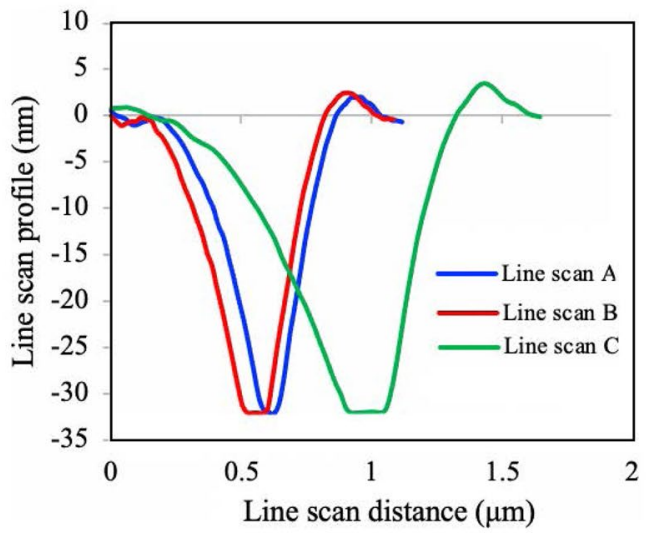

dry maximum static strain. Fatigue tests were interrupted at regular time intervals to analyse surface related damage during fatigue and failure mechanisms using reflected light and SEM integrated with EDX. In this study, using a data logger connected to the load cell in the fatigue rig, the load-time response during fatigue tests is recorded (Fig. 2(b)). When the first sudden load drop occurs (indicating failure in one of the samples), the fatigue test was interrupted and the samples were checked under a light microscope to identify the failed sample which was removed. The fatigue test is then carried on until the next load drop occurs. The same procedure was used for the rest of the samples until the all have failed. Although fatigue tests have been conducted for multiple samples with the above procedure, a fatigue test was repeated using a single sample for each strain level to check consistency; each test is therefore repeated 5 times. As the bending fatigue tests are conducted under strain control mode, the applied load, required to keep the given deflection constant, decreases with the number of cycles. In other words, stiffness degradation of composites during the fatigue tests can be confirmed directly via the output from the fatigue test rig.

\section{Strain-life curves}

In this study a power law relationship between maximum initial strain $\left(\varepsilon_{\max , \mathrm{i}}\right)$ and fatigue life was used.

$e_{\max , \mathrm{i}}=K\left(\log N_{\mathrm{f}}\right)^{-A}$

where $N_{\mathrm{f}}$ is the number of cycles to failure, $K$ and $A$ are constants. The constants can be determined by plotting the strain versus number of cycles to failure and fitting equation (1) to the data. In order to determine the life time diagram, five specimens were tested at a minimum of seven separate levels of imposed strain. Also for measuring the monotonic strength and its corresponding deflection/strain level for the selected test method, five specimens were initially tested under 3 PB to failure. The fatigue failure criterion was defined as the onset of delamination. The strain-life fatigue test results for GFRP composite along with the corresponding fits to equation (1) are shown in Fig. 3 in which each data point indicates one valid flexural fatigue test. Comparing $\varepsilon-\mathrm{N}$ curves obtained in air with sea water environment provides an indication of the durability of these materials and
Fig. 8 AFM image of a residual indentation print from an indentation carried out on the constrained epoxy resin, highlighting locations of line scans, (b) Line scans $\mathbf{A}, \mathbf{B}$ and $\mathbf{C}$ (a)

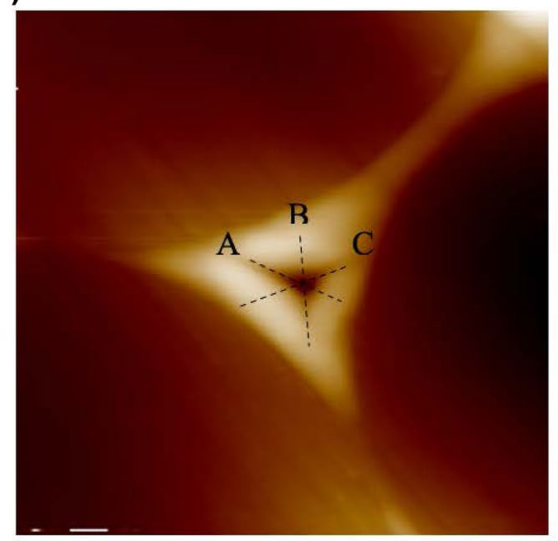

(b)

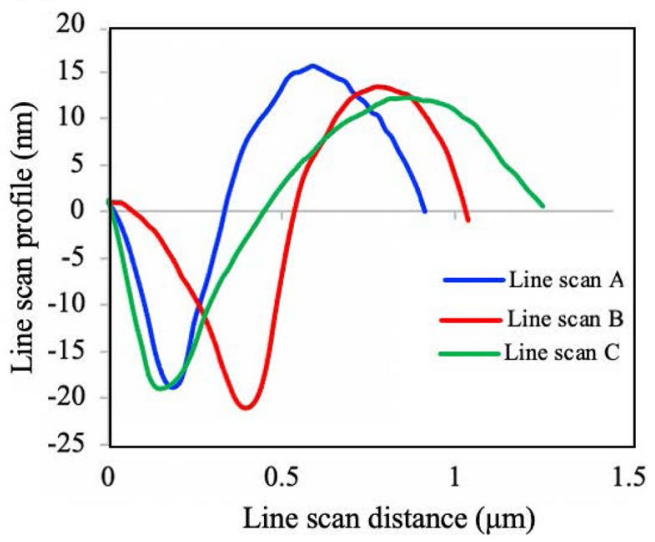




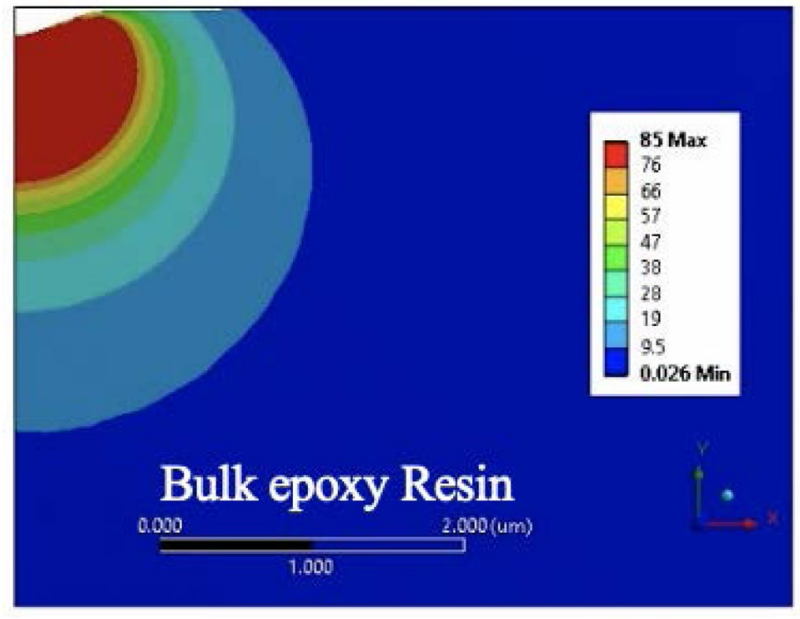

Fig. 9 FE calculated Von Mises stress field of Nano indentation of bulk epoxy resin

clearly reveals the influence of the environment on reducing fatigue life. In this study, samples in high cycle fatigue (circled in Fig. 3) where the difference between fatigue life in air and sea water is significant $\left(10^{5}<\mathrm{N}_{\mathrm{f}}<10^{6}\right)$, are chosen for nanoindentation characterization.

\section{Nanoindentation Test}

In this work, the depth sensing nanoindentation testing was conducted using a Hysitron Triboindenter fitted with the Berkovich diamond indenter (tip end radius $250 \mathrm{~nm}$ ). To make sure that the Nano indentation results are not influenced by errors due to the shape of indenter, standard fused silica specimen was initially used to calibrate the tip area function. The tests were performed under displacement control mode and indentation velocity of $0.04(\mu \mathrm{m} / \mathrm{s})$ using a single cycle indentation (load-hold-unload) protocol and during each cycle, a $5 \mathrm{~s}$ hold was imposed at the peak displacement. In addition, before the indentation testing, both unreinforced epoxy resin and fiber-matrix composites specimens were held for $24 \mathrm{~h}$ inside the nanoindentation enclosure in order to minimize the effect of thermal drift and to match the specimen temperature with the environment. In this study, atomic force microscopy (AFM) scans were also used to identify the occurrence of material pile up.

\section{Calculation of mechanical properties using nano indentation}

The analysis of load-displacement curves obtained by nanoindentation on materials provides the contact modulus and hardness following the procedure outlined by Oliver and Pharr [15]. In this method, Hardness $(H)$ is calculated by:

$H=\frac{P \max }{A_{c}}$

where Pmax is maximum applied load and $A_{c}$ is the contact area at the indentation depth (projected area between the indenter and specimen). The contact stiffness $(S)$ is calculated from the initial slope of unloading curve. This is related to the contact modulus $\left(E_{r}\right)$ using equation:

$S=\frac{d p}{d h}=\frac{2 E_{r} \beta \sqrt{A_{c}}}{\sqrt{\pi}}$

where $\beta$ is correction factor (1.034 for Berkovich indenter tip) and the value is applicable for both elastic-plastic and perfectly elastic materials. According to the Oliver and Pharr method, the contact area is calculated via the area function for the indenter tip geometry used. This function states the contact area as a function of contact depth $\left(h_{c}\right)$, which for the perfect sharp geometry of the indenter is given by

$A=F\left(h_{c}\right)=24.56 h_{c}^{2}$

In order to consider the bluntness of the tip, Oliver \& Pharr proposed the area function which is mainly applicable for Berkovich tip is given as

$\mathrm{A}=24.5 \mathrm{~h}_{\mathrm{c}}^{2}+\mathrm{c}_{1} \mathrm{~h}_{\mathrm{c}}{ }^{1}+\mathrm{c}_{2} \mathrm{~h}_{\mathrm{c}}^{0.5}+\mathrm{c}_{3} \mathrm{~h}_{\mathrm{c}}^{0.25} \ldots$ (a)

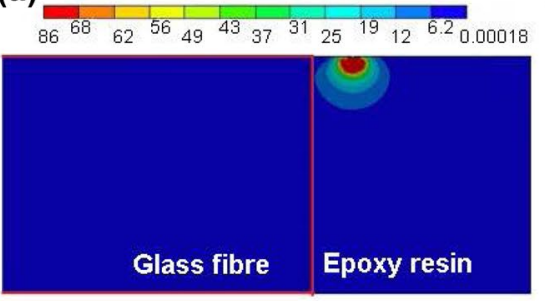

(b)

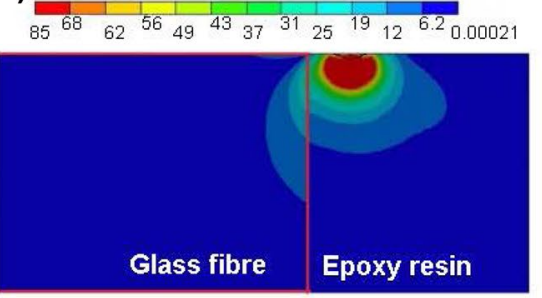

(c)

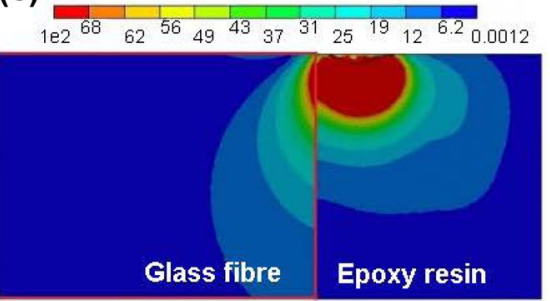

Fig. 10 Evolution of von Mises stress fields in the glass fibre sections through the F/M interface during the indentation depths of (a), 50 nm, (b) $100 \mathrm{~nm}$ and (c) $200 \mathrm{~nm}$ 
Fig. 11 (a) Experimentally and (b) Numerically generated Load displacement curves obtained from indentation on unconstrained and constrained epoxy resin (a)

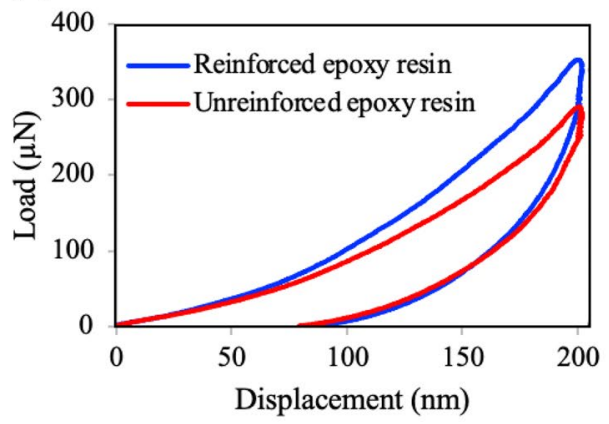

(b)

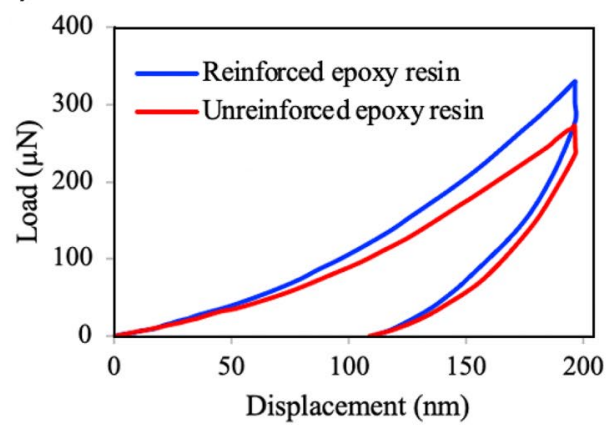

The contact depth in above equation is calculated based on Sneddon's expression [28].

$h_{c}=h_{\max }-\varepsilon \frac{p_{\max }}{\frac{d p}{d h}}$

where $P_{\max }$ and $h_{\max }$ are the maximum load and displacement respectively and $\varepsilon$ is 0.75 for a paraboloid of revolution [29]. However, in case of FE calculated load-displacement curve in this study, the contact area $\left(\mathrm{A}_{\mathrm{c}}\right)$ is determined in the FE model from the last point of contact at maximum load.

To calculate the modulus of the sample $\left(E_{s}\right)$, below equation is used:

$\frac{1}{E_{r}}=\frac{1-v_{s}^{2}}{E_{s}}+\frac{1-v_{i}^{2}}{E_{i}}$

where $E_{i}$ and $v_{i}$ are the modulus and the Poisson's ration of the diamond indenter and $E_{s}$ and $v_{s}$ are the modulus and the Poisson's ration of the sample.

\section{Atomic force microscopy}

Atomic force microscopy (AFM) is a very high resolution type of scanning probe microscopy (SPM) and works on the basis of surface sensing by means of a sharp tip on a micro-machined silicon probe. This tip is used to map the contours of the sample by raster scanning across the surface line by line. In this study, the Hysitron Triboindenter used for nanoindentation of composite material, is capable of insitu SPM imaging. This allows a detailed observation and characterisation of the test area of the surface by having a pre and post-test observation. By scanning the surface of the sample with a physical probe, the indenter tip in the case of Triboindenter, SPM images can be obtained. The sharp indenter tip moves mechanically across the sample surface in a raster scan pattern. During the scan, the detector of the Triboscanner uses a feedback loop to maintain the scan load constant and records information about the sample such as height. In this study, data visualisation and analysis were accomplished using post-processed AFM data analysis software of Gwyddion [30] to identify the heights and widths of the pile-ups which was shown schematically in Fig. 1. It should be noted that the tip is relatively blunt compared to conventional AFM tips and the scanning contact load is much higher $(1.8 \mu \mathrm{N})$ which can generate surface damage. This means that the AFM images do not have the same high resolution as conventional AFM but are very suitable for measuring the size and shape of indentation impressions which are more than $100 \mathrm{~nm}$ in diameter. Since the nanoindenter head is mounted on the AFM scanner and the sample
Fig. 12 Comparison between the FE and EXP calculated Load displacement curves obtained from indentation on (a) constrained and (b) unconstrained epoxy resin (a)

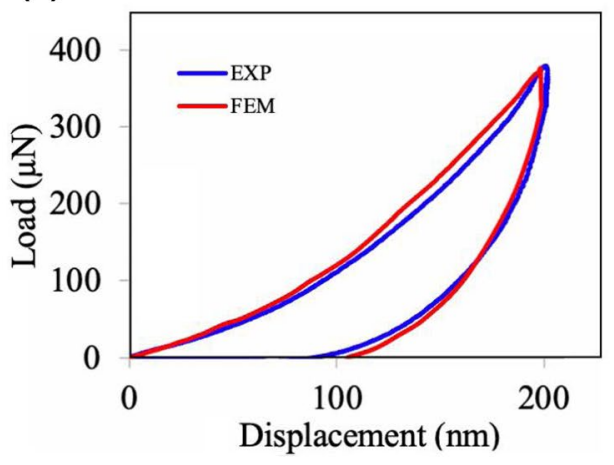

(b)

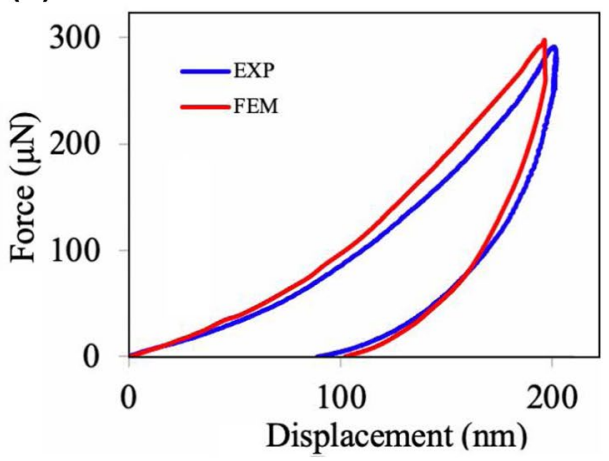


Table 3 Ratio of contact area calculated from FEM to the contact area calculated from Oliver and Pharr method

\begin{tabular}{llll}
\hline Epoxy Resin & $\begin{array}{l}\text { Contact area } \\
\text { (Oliver and } \\
\text { Pharr method) }\end{array}$ & $\begin{array}{l}\text { Contact area } \\
\text { (FEM method) }\end{array}$ & $\begin{array}{l}\text { Area } \\
\text { correction } \\
\left(\frac{A_{F E M}}{A_{O P}}\right)\end{array}$ \\
\hline Unconstrained & $1.084\left(\mu \mathrm{m}^{2}\right)$ & $1.17\left(\mu \mathrm{m}^{2}\right)$ & 1.08 \\
Constrained & $1.022\left(\mu \mathrm{m}^{2}\right)$ & $1.43\left(\mu \mathrm{m}^{2}\right)$ & 1.4 \\
\hline
\end{tabular}

is not moved from indentation to imaging location it is possible to locate such small indents reliably.

\section{Viscoplasticity Parameters}

In order to analyse the time dependent response of the polymeric specimen (epoxy resin) under nanoindentation, viscoplasticity models were applied in the numerical simulation. To account for the effect of viscoplasticity, two methods based on Perzyna and modified time hardening (creep) were implemented. For the Perzyna model, the stress-strain response of the epoxy resin under tension tests at various strain rates (Fig. 4(a)) were used to determine the parameters. This was done based on the ideas presented by Perzyna [31-33]. The model assumes that the plastic strain rate $\left(\hat{\varepsilon}_{\mathrm{pl}}\right)$ is a function of a hardening/softening parameter $(\mathrm{m})$, a material viscosity parameter $(\gamma)$, and the static yield stress $\left(\sigma_{0}\right)$. The stress-strain rate graph is created and fitted with the Perzyna material model of viscoplasticity to identify the required parameters (Table 1). To identify the modified time hardening parameters, reported in Table 1, the variation of strain versus time at the stress level of $10 \mathrm{MPa}$ (obtained from a creep test as shown in Fig. 4(b)) was determined and fitted with the modified time hardening model.

\section{Finite Element Modelling}

In this study, in order to reproduce the Nano indentation experiment through the simulation, the Finite Element software ANSYS was used. Due to the symmetric nature of the indenter and fibre matrix composite, a half 3D model was adopted to reduce the computational time. The model was further simplified to a quarter 3D model when indentation was simulated on the bulk (unreinforced) epoxy resin and glass fibre.

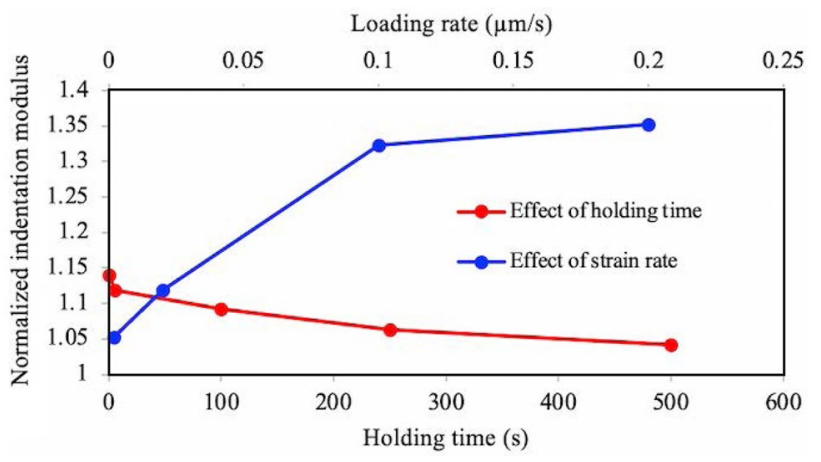

Fig. 13 Effect of loading rate (at the constant hold time of zero) and holding time (at the constant loading rate of $0.2 \mu \mathrm{m} / \mathrm{s}$ ) on elastic modulus calculated using the FEA of nano indentation on bulk epoxy resin, Normalized modulus is the ratio of indentation modulus calculated from the FE calculated load displacement curve over the macroscopic tensile modulus

\section{D FEM}

In nanoindentation modelling of bulk epoxy resin, glass fibre as well as composite microstructure, a 3D model was set up where the indenter was modelled as a conical indenter (semi-vertical angle of $70.3^{\circ}$ ) with the same projected area to depth ratio as the pyramidal Berkovich indenter used in Nano indentation experiment. It has been shown that modelling the conical indenter yield the same load displacement behaviour as the pyramidal Berkovich indenter and only the stress distribution is different at indenter edges [34]. To build the model, 3D structural solid element type of SOLID185 which has nonlinear capability (large strain and deformation) is used for the entire regions of the indenter and the indented sample. The element can be integrated with CONTA173 and TARGE170 elements to define the surface-to-surface contact. The material properties are viscoplastic for the epoxy resin matrix (Table 1) and elastic-plastic for the glass fibres (Table 2). The indenter was also modelled as deformable body with its elastic properties the same as diamond (Young's modulus of $1140 \mathrm{GPa}$ and Poisson's ratio of 0.08). Since a large localized deformation occurs in the contact region beneath the indenter, finer mesh was used close to the contact zone, while a coarser mesh was used outside this region. The appropriate number of elements and element size were obtained by improving the mesh density using

Table 4 Experimentally calculated indentation modulus of unreinforced and reinforced epoxy resin and the effect of pile up (using FEM) and hydrostatic stress

\begin{tabular}{llll}
\hline Elastic modulus (GPa) & $\begin{array}{l}\text { Nano-indentation Oliver\& Pharr (corrected by } \\
\text { area correction in Table 3) }\end{array}$ & $\begin{array}{l}\text { Pile up effect } \\
\text { effect }\end{array}$ & $\begin{array}{c}\text { Difference } \\
\text { Unconstrained resin }\end{array}$ \\
Constrained resin & $5.22 \pm 0.3$ & 5.02 & 4.21 \\
\hline
\end{tabular}


Fig. 14 AFM image of a residual indentation print from an indentation carried out on the F/M interface, highlighting locations of line scans, (b) Line scans $\mathbf{A}, \mathbf{B}$ and $\mathbf{C}$ (a)

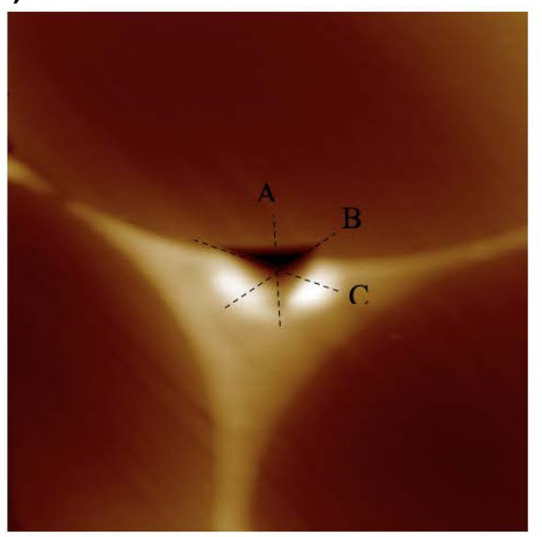

(b)

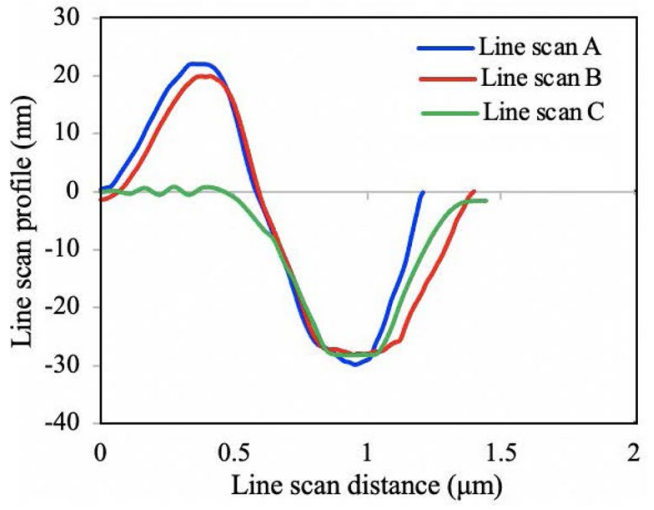

the convergence study of the load-displacement curve. The friction coefficient between the tip indenter and the upper surface of indented material was set to $0.1[35,36]$.

Based on a hexagonal array of fibres in Fig. 5 (i.e. one fibre is surrounded by six equally-spaced fibres), discrete cylindrical regions representing glass fibres were added to the bulk epoxy resin system (Fig. 6). Beyond the 4 unit cells originally designed in the FE model (Fig. 6(a)), a model has been developed which included further unit cells containing more discrete cylindrical fibres, however, the results from these models did not change significantly from the FE model that was initially used. Based on microstructural analysis of the composite sample using SEM, the diameter of glass fibres and the spacing between them was set to 8 $\mu m$ and $0.5 \mu m$ respectively. The glass fibres were assumed to be perfectly bonded with epoxy resin matrix. In terms of boundary conditions, on the bottom side of 3D model of the fibre-matrix composite specimen, each node is connected with a spring-damper element aligned upright and the other side of spring-damper element is constrained. The stiffness coefficient of the spring element is calculated by fitting elastic modulus of glass fibre and epoxy resin.

FE simulation was conducted at three different locations, the first indentation with the cone indenter centred on the fibre/matrix interface. The indenter was displaced in both directions from the interface in $0.9 \mu \mathrm{m}$ increments ( 1 indentation on the fibre and 1 indentation in the matrix). Following the experiment (Sect. 2.3), a displacement control mode (analogous to the method used in the experiment) was used for the movement of the indenter. The analysis of the FE calculated load-displacement curve provides the contact and indentation modulus of the indented material following the procedure based on the Oliver and Pharr method. The FE simulation in this study was also used to correct the effect of
Fig. 15 FE calculated Von Mises stress field of Nano indentation on Fibre/Epoxy resin interface at the maximum indentation depth of $200 \mathrm{~nm}$
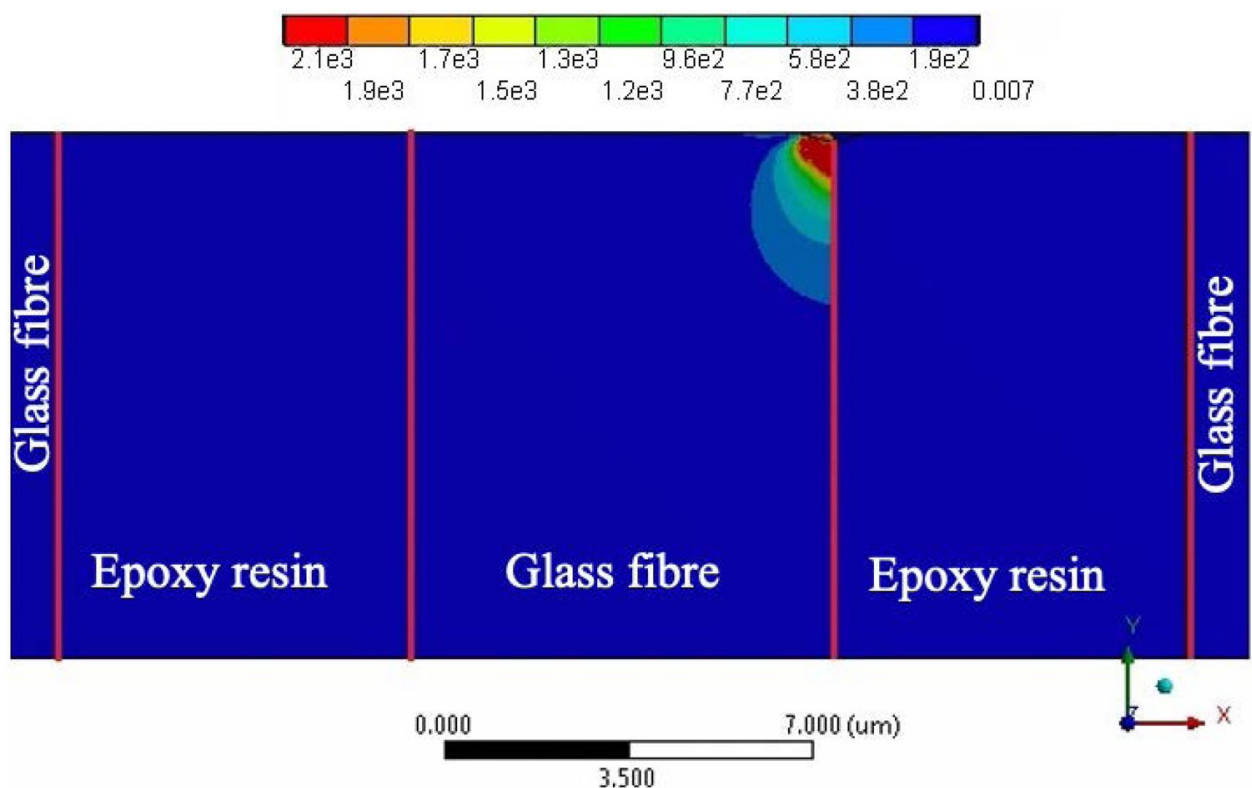
Fig. 16 Experimentally and numerically generated Load displacement curves obtained Matrix interface from indentation on Fibre/

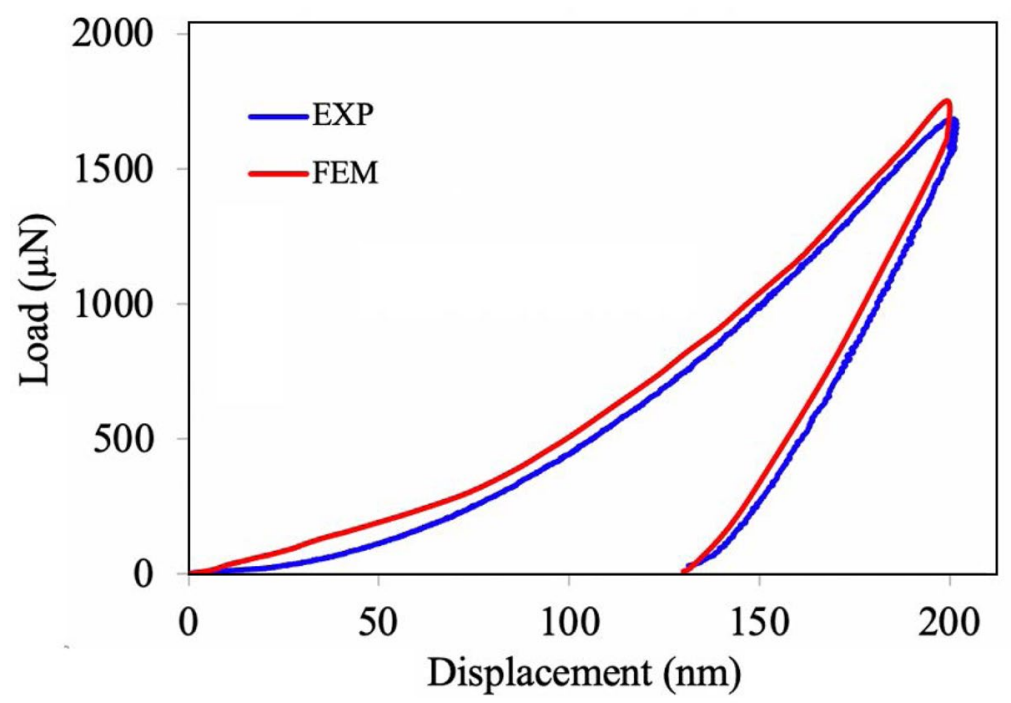

pile up on the Nano indentation of constituents (epoxy resin and $\mathrm{F} / \mathrm{M}$ interface). Therefore instead of using Oliver and Pharr method to calculate the contact area, it was estimated directly from the FE model by finding the last point of contact at maximum load, and therefore, an area correction was applied to the experimental nanoindentation test results to calculate the indentation modulus.

\section{Results and Discussion}

\section{Numerical and Experimental Results of Nano Indentation Test}

\section{Unreinforced and in situ epoxy resin}

The AFM images of the residual indentation print on unreinforced (bulk) and reinforced (in situ) epoxy resin and the amounts of pile up are shown in Figs. 7 and 8 respectively. Compared to the amount of pile up in unreinforced epoxy resin, the indentation on the reinforced resin causes more pile up. This is due to the mechanical constraining effect of glass fibres. In order to investigate the constraining effect of glass fibres on the mechanical properties of epoxy resin, both FE and experimental nanoindentation tests are used.

Table 5 Ratio of contact area calculated from FEM to the contact area calculated from Oliver and Pharr method (area correction) used to correct the effect of pile up

\begin{tabular}{llll}
\hline & $\begin{array}{l}\text { Contact area } \\
\text { (Oliver and Pharr } \\
\text { method) }\end{array}$ & $\begin{array}{l}\text { Contact area } \\
\text { (FEM method) }\end{array}$ & $\begin{array}{l}\text { Area correction } \\
\left(\frac{A_{F E M}}{A_{O P}}\right)\end{array}$ \\
\hline F/M interface & $0.938\left(\mu m^{2}\right)$ & $1.294\left(\mu m^{2}\right)$ & 1.38 \\
\hline
\end{tabular}

In order to model the microstructure of the composite, epoxy resin regions (pockets) with the circular array of adjacent fibres were used. The indents were positioned at the centre of the epoxy pockets similar to the fibre packing arrangement shown schematically in Fig. 6(b). FE calculated stress fields developed during the indentation process on both unreinforced and reinforced epoxy resin have been investigated (Figs. 9 and 10). The von Mises stress fields developed in the FE models of reinforced epoxy resin for three different indentation depths are shown in Fig. 10 providing an insight into the stress transfer between insitu composite constituents when characterizing the in-situ epoxy resin. It can be seen that, as the indentation depth increases, substantial stresses are developed in the fibre sections through the fibre-matrix interface. Correspondingly, the experimentally and numerically generated load displacement curves for this indentation process are shown in Figs. 11 and 12 along with load displacement curves from the nano indentation on the unreinforced epoxy resin. For low values of displacement (less than $50 \mathrm{~nm}$ ), the two curves (unconstrained and constrained) are overlapping meaning that the mechanical constraining effect of fibres is not dominant at these depths, however, when the indentation depths increase (more than $50 \mathrm{~nm}$ ), stress transfer to the neighbouring glass fibres occurs as shown in Fig. 10. That's why in Fig. 11, difference between the load displacement curves for the contact depth bigger than $50 \mathrm{~nm}$

Table 6 FE and experimentally calculated contact modulus of F/M interface

\begin{tabular}{llll}
\hline Contact modulus $(\mathrm{GPa})$ & $E_{r}(\mathrm{FEM})$ & $E_{r}(\mathrm{OP})$ & Pile up effect $(15 \%)$ \\
\hline F/M interface & 24.1 & $32 \pm 8$ & $27.24 \pm 8$ \\
\hline
\end{tabular}


(a)

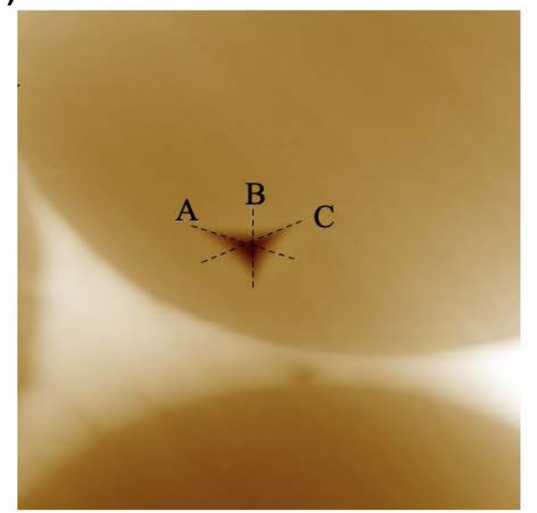

(b)

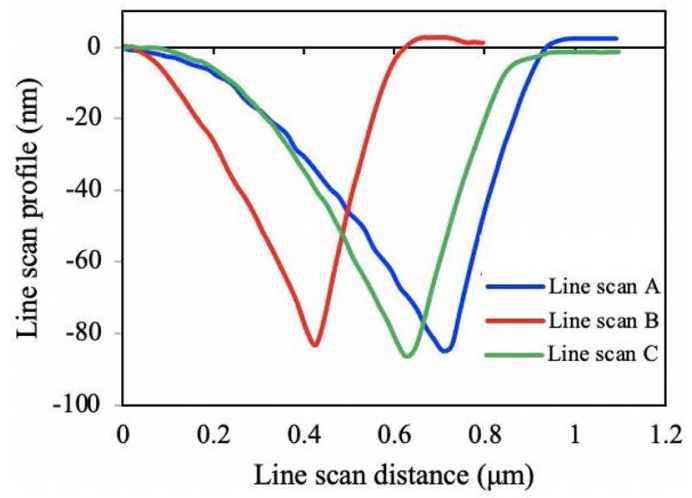

Fig. 17 AFM image of a residual indentation print from an indentation carried out on the in situ glass fibre, highlighting locations of line scans, (b) Line scans $\mathbf{A}, \mathbf{B}$ and $\mathbf{C}$

is observed. In other words, the maximum load required to achieve the displacement of $200 \mathrm{~nm}$ is higher when indenting constrained resin compared to unconstrained one. In addition, compared to the unconstrained epoxy resin, conducting indentation on constrained epoxy resin results in a steeper slope in the initial part of unloading curve indicating an increase in the contact stiffness.

When indenting constituents in polymer composite, it is shown that due to the effect of pile up (Figs. 7, 8 and 14), the Oliver and Pharr method underestimates the contact area. In this study, because of the viscoplasticity recovery which the epoxy resin experiences on reduction of the maximum indentation load, methods of calculating the projected contact area [23, 37-40] or depth-corrected contact area [23, 37, 41] failed to correct the effect of material pile up on indentation modulus. In fact, the height of the measured pile-up is a not representative of the state of pile-up under the indenter at

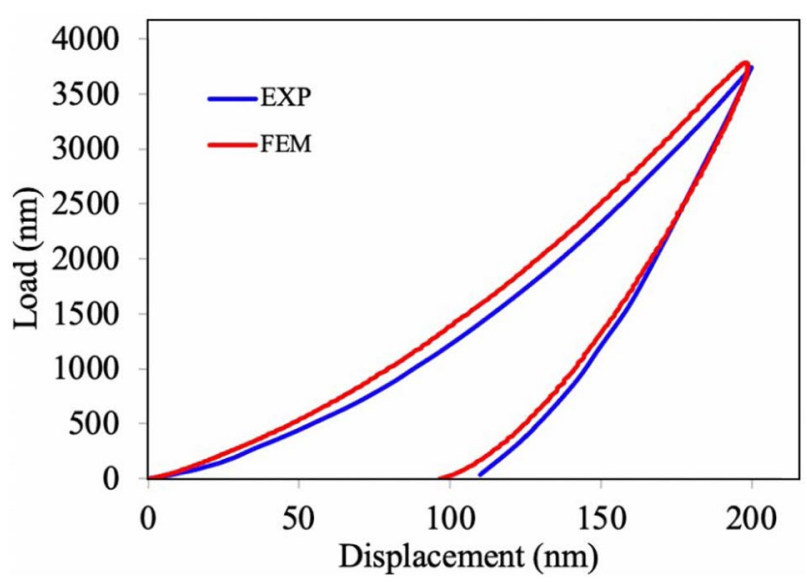

Fig. 18 Experimentally and numerically generated Load displacement curves obtained from indentation on the Fibre maximum indentation load. In addition, the Oliver and Pharr method does not take into account the effect of viscoplasticity, therefore, in order to correct the effect of above phenomena for the measurement of elastic modulus, the projected contact area was estimated from the FE model.

In Fig. 12, FE calculated load displacement curve is compared with experimentally generated load displacement curves. The small difference between experimental load displacement curves with the computed results from the FE model might be due to the effect of surface roughness, adhesion force and indentation process associated factors (e.g. size-scale effects associated with low-depth indentation) which have not been considered in the numerical model. The maximum load reached by all the Nano indentation experiments on reinforced and unreinforced resin only varies between $340-360 \mu \mathrm{N}$ and $280-300 \mu \mathrm{N}$ respectively indicating that the resulting data curves for all indentations are relatively consistent and reproducible due to the careful and uniform process of polishing the sample. The agreement between numerical and experimental results validates the viscoplasticity parameters introduced into the FE model.

In this study, in order to correct the effect of pile up, the ratio of contact area calculated from the FE model to the contact area calculated using the Oliver and Pharr method is used (Table 3) and therefore an area correction was applied to the experimental indentation test data. Due to the mechanical constraining effect of fibres and therefore higher amount

Table 7 Area correction applied on experimental indentation test data to correct the effect of pile up

\begin{tabular}{llll}
\hline & $\begin{array}{l}\text { Contact area } \\
\text { (Oliver and Pharr } \\
\text { method) }\end{array}$ & $\begin{array}{l}\text { Contact area } \\
\text { (FEM method) }\end{array}$ & $\begin{array}{l}\text { Area correction } \\
\left(\frac{A_{F E M}}{A_{O P}}\right)\end{array}$ \\
\hline Glass fibre & $0.61\left(\mu \mathrm{m}^{2}\right)$ & $0.61\left(\mu \mathrm{m}^{2}\right)$ & 1.00 \\
\hline
\end{tabular}


Table 8 Elastic modulus of in situ glass fibre

Contact modulus $E$ (FEM) $E(\mathrm{OP}) \quad$ Tensile modulus Difference (GPa)

\begin{tabular}{|c|c|c|c|}
\hline $\begin{array}{l}\text { In situ Glass } \\
\text { fibre }\end{array}$ & 61 & $60.22 \pm 3 \quad 72$ & $-16.3 \%$ \\
\hline
\end{tabular}

of pile up in the reinforced epoxy resin compared to unreinforced epoxy resin, this ratio is higher when indentation is performed on reinforced epoxy resin. The elastic modulus of epoxy resin (both unreinforced and reinforced) calculated from the experimentally generated load displacement curves are corrected by the area correction and reported in Table 4 . It must be noted that, the elastic modulus of the bulk and reinforced epoxy resin has been calculated by averaging data from the 20 indentations using the Oliver and Pharr method and the mean value of modulus was calculated as $5.22 \mathrm{GPa}$ and $8.65 \mathrm{GPa}$ with a standard deviation of 0.3 and 0.6 respectively. Due to the fact that epoxy resin regions are not perfectly circular and therefore the initial point of contact between indenter tip and epoxy resin rich region is not exactly located at its centre, a bigger standard deviation is observed.

After accounting for the effect of material pile up (using the area correction in Table 3) and hydrostatic stress using a relation detailed in $[23,42]$, the remaining difference of about $12 \%$ between the indentation modulus of unreinforced epoxy resin (i.e. $4.21 \mathrm{GPa}$ ) and macroscopic tensile modulus (i.e. $3.78 \mathrm{GPa}$ ) is mainly due to the effect of viscoplasticity. Although the effect of creep has been considered by addition of a constant displacement hold segment between the loading and unloading segments (i.e. $5 \mathrm{~s}$ hold segment), the FE analysis of indentation on bulk epoxy resin at various holding times and/or displacement rate shows that increasing holding time or reducing strain rate results in an indentation modulus of the epoxy resin which compares very well with the bulk tensile modulus. As it can be seen in Fig. 13, the results can be produced free from the effect of time

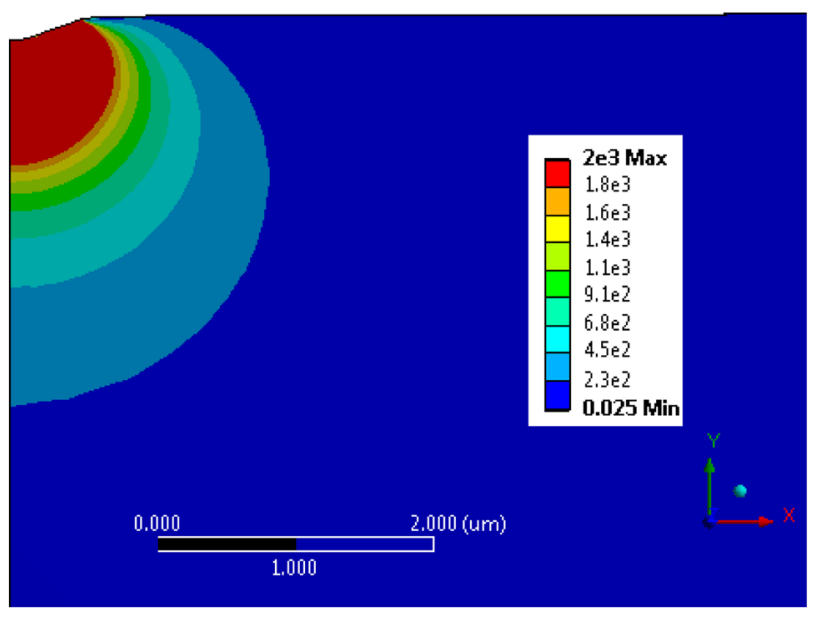

Fig. 19 FE calculated Von Mises stress field of Nano indentation on bulk glass fibre

dependent deformation behaviour of epoxy resin by either increasing holding time by $500 \mathrm{~s}$ or reducing the displacement rate by $0.002(\mu \mathrm{m} / \mathrm{s})$. It was found that reducing the effects of the viscoplastic deformation can lead to reductions of the modulus of the order of $10-12 \%$.

In addition, as it can be seen from Table 4, the indentation modulus of in situ epoxy resin is 55\% higher compared with bulk epoxy resin. This is mainly due the mechanical constraining effect of surrounding reinforced fibres as well as stresses from the high temperature curing process. Extracting indentation modulus from the FE calculated load displacement curves in Fig. 11(b), shows that the difference between the indentation modulus of constrained and bulk epoxy resin is $40 \%$ which is due to the mechanical constraining effect of glass fibres. As a result, the remaining difference of about $15 \%(55 \%-40 \%)$ can be related to the high temperature curing process associated with composite manufacture which has not been considered in the FE analysis. Although the constraining effect can be reduced using lower indentation depth, the effect of tip blunting of the (a) \begin{tabular}{c|cccccc}
$1.9 \mathrm{e} 3$ & $1.5 \mathrm{e} 3$ & $1.2 \mathrm{e}$ & $8.6 \mathrm{e} 2$ & $5.1 \mathrm{e} 2$ & $1.7 \mathrm{ee}$ \\
$2.1 \mathrm{e} 3$ & $1.7 \mathrm{e} 3$ & $1.4 \mathrm{e} 3$ & $1 \mathrm{e} 3$ & $6.8 \mathrm{e} 2$ & $3.4 \mathrm{e} 2$ & 0.013
\end{tabular}

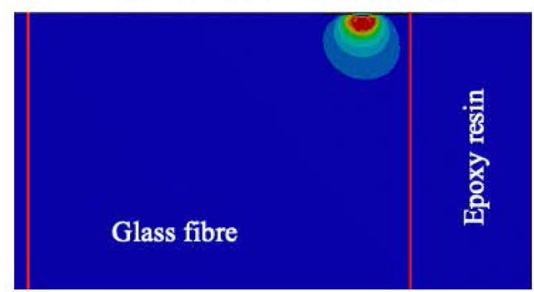

(b)

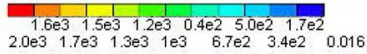

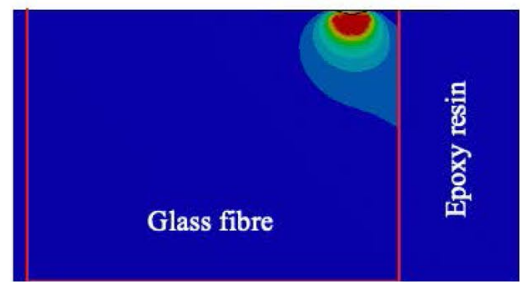

(c)

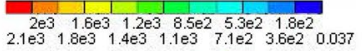

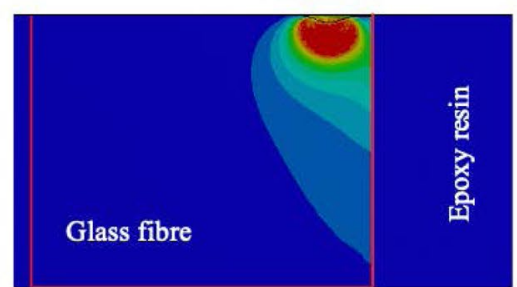

Fig. 20 Evolution of von Mises stress fields in the glass fibre sections through the F/M interface during the indentation depths of (a), $20 \mathrm{~nm}$, (b) $100 \mathrm{~nm}$ and (c) $200 \mathrm{~nm}$ 


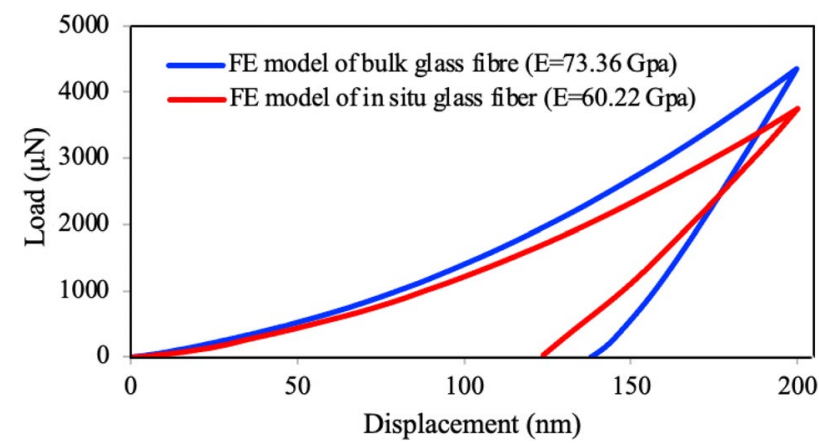

Fig. 21 FE calculated load displacement curves

indenter and surface roughness might be difficult to account for reliably meaning that characterizing the nano mechanical response of composite constituents (in particular in situ epoxy resin) irrespective of the constraining effect of fibres is impossible.

\section{Fibre-matrix interface}

The AFM image of a residual indentation print on the glass fibre-epoxy resin interface with a visible amount of pile up in the epoxy resin region is shown in Fig. 14. To understand how the stress is developed through the constituents during the indentation on F/M interface, the von Mises stress field from FE results is shown in Fig. 15. It is clear that due to the higher stiffness of glass fibre compared to the epoxy resin, a higher value of stress is localized on the glass fibre section. Similar to the Sect. 3.1.1, in order to account for the effect of pile up on the measurement of contact modulus, a FE and experimental load displacement curve is generated (Fig. 16). The relatively good agreement between numerical and experimental curves validates the viscoplasticity parameters used in the FE model. As a result, the contact area can be estimated from the FE model. It must be noted that, apart from the effect of surface roughness, fibre-matrix adhesion and the curing process, depending on whether the Berkovich indenter with the pyramid flat or edge sides come in contact with the fibres, a difference between experimental load displacement curves and the FE computed results can be observed. The ratio of contact area calculated from the FE model to the contact area calculated using the Oliver and Pharr method is shown in Table 5. As a result, the experimentally calculated contact modulus of the $\mathrm{F} / \mathrm{M}$ interface is corrected (Table 6). It must be noted that, a relatively big standard deviation is observed for the contact modulus of $\mathrm{F} / \mathrm{M}$ interface. This is mainly due to the topography of surface following the sample preparation (i.e. grinding and polishing). The existence of fibre-matrix relief between the glass fibre and epoxy resin following the composite sample preparation is due to the difference in the amount of surface removal of each phases.

\section{In situ glass fibre}

The AFM image of a residual indentation print on the insitu glass fibre is shown in Fig. 17. Following the same method in previous sections, FE and experimental load displacement curves are generated (Fig. 18) and the resultant indentation modulus given the area correction factor (Table 7) is reported in Table 8. The contact area estimated by Oliver and Pharr method is similar to the FE calculated contact area. In order to understand how the indentation modulus of in situ glass fibre $(\mathrm{E}=60.22 \mathrm{GPa})$ extracted from Nano indentation test is affected by the soft neighbouring phase of epoxy resin (i.e. $16.3 \%$ difference between the indentation modulus of glass fibre and the elastic modulus used to define the property in the FE model), the indentation simulation process on a bulk glass fibre was also done and the von Mises stress field is shown in Fig. 19. The von Mises stress distributions for three indentation depths on the in situ glass fibre are also shown in Fig. 20 providing an insight into the stress (a)

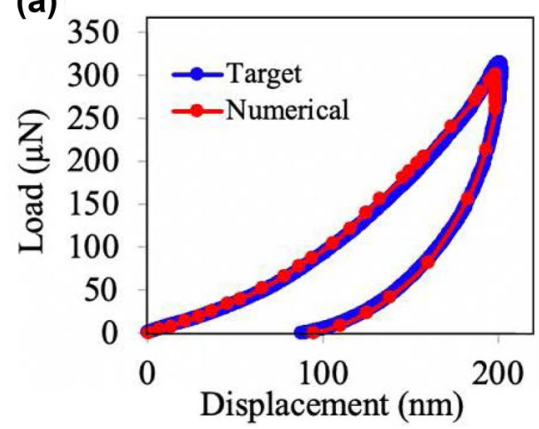

(b)

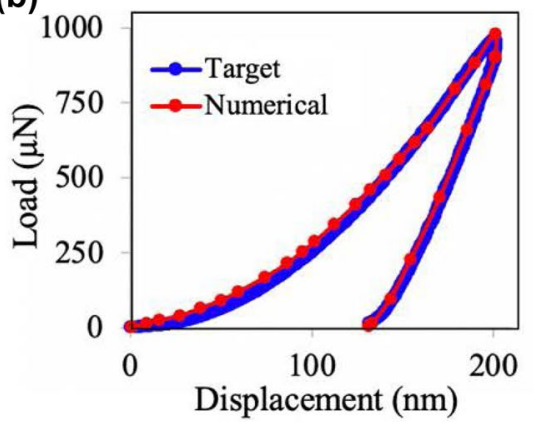

(c)

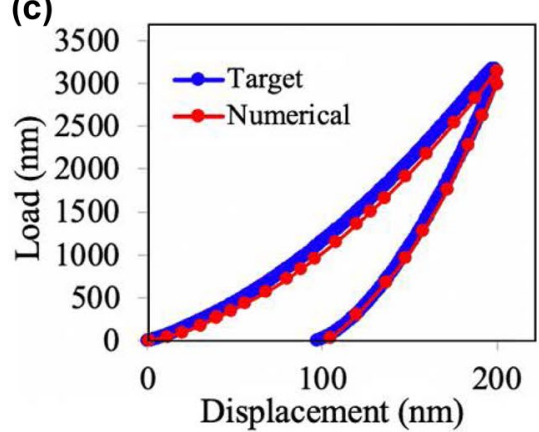

Fig. 22 Convergence between target data (experimental nano indentation) and numerical data (FEM) load displacement curves of composite constituents of fatigue loaded sample (a) in situ epoxy resin, (b) F/M interface and (c) in situ glass fibre 
Table 9 Obtained contact modulus of composite constituents used in FE after convergence with target

\begin{tabular}{llllc}
\hline Properties & environment & In situ epoxy resin & In situ Glass fibre & F/M interface \\
\hline Contact modulus (GPa) & Sea water & $5.83 \pm 0.62$ & $51.2 \pm 2.4$ & $15.8 \pm 3.5$ \\
Contact modulus (GPa) & air & $6.5 \pm 0.5$ & $58.1 \pm 2.3$ & $24.8 \pm 4.5$ \\
\hline
\end{tabular}

transfer between composite constituents when characterizing the in-situ glass fibre. It can be seen that, as the indentation depth increases, stresses develop in the epoxy resin sections through the fibre-matrix interface. The load displacement curve obtained from the indentation simulation process on the bulk and in situ glass fibre is shown in Fig. 21. For very low values of displacement (less than $20 \mathrm{~nm}$ ), the two curves (bulk glass fibre and in situ glass fibre) overlap meaning that the effect of the compliant epoxy resin on the properties of glass fibre is negligible, however, when the indentation depth increases (more than $20 \mathrm{~nm}$ ), stress transfer into the neighbouring epoxy resin region occurs as shown in Fig. 20. That's why a difference between the load displacement curves for contact depth bigger than $20 \mathrm{~nm}$ is observed in Fig. 21. In other words, the maximum load required to achieve the maximum displacement of $200 \mathrm{~nm}$ is higher for the bulk glass fibre compared to the in situ glass fibre. In addition, compared with the in situ glass fibre, conducting indentation on a bulk glass fibre results in a steeper slope in the initial part of unloading curve indicating an increase in the contact stiffness. Following the Oliver and Pharr method to calculate the elastic modulus from the load displacement curves, FE generated load displacement curves were used to extract the elastic modulus of bulk glass fibre. This results in the elastic modulus of $73.36 \mathrm{GPa}$ for the bulk glass fibre showing less than $2 \%$ difference with the glass fibre properties used to define into the FE model.

\section{Nano Indentation Testing on Composite Samples Affected by Fatigue}

In order to determine the mechanical properties of constituents (i.e. in situ epoxy resin surrounded by fibres, an in situ glass fibre and the F/M interface) of composite samples subjected to high cycle fatigue loads which were mentioned in section 2.2, similar nanoindentation experiments as

Table 10 Obtained viscoplasticity model parameters of fatigue loaded composite sample in sea water used in FE after convergence with target

\begin{tabular}{lllll}
\hline Model & Parameters & & \\
\hline Modified Time Hardening & $C_{1}$ & $C_{2}$ & $C_{3}$ & $C_{4}$ \\
$\varepsilon_{r}=\frac{C_{1} \times \sigma^{C_{2}} \times t^{c_{3}+1}\left(\exp \left(-\frac{C_{4}}{T}\right)\right)}{C_{3}+1}$ & $3.68 \mathrm{e}-5$ & 1 & -0.82 & 0 \\
\hline
\end{tabular}

described in section 2.3 were carried out on composite samples that had failed due to fatigue. This has been done in order to obtain the load-displacement curves at each target data. As mentioned earlier, due to the viscoplasticty properties of the matrix phase as well as the effect of pile-up, the analysis of load displacement curves based on the Oliver and Pharr method cannot be used to extract the mechanical properties of the composite constituents, therefore, an inverse FEM model interfaced with a MATLAB code was used to obtain the modulus of elasticity as well as modified time hardening material constants of the composite constituents of fatigue loaded test coupons. The code automatically feeds the input material properties data to FE software and automatically runs simulations to establish a convergence between the numerical load-displacement curve and the target data (i.e. experimental load-displacement curves). In this approach, mechanical properties of the fibres and epoxy resin (Table 2) as well as material model constants (Table 1) were used as the starting parameter values fed into the FE software and it was found that an optimization method based on a non-linear least-squares curve fitting function (LSQNONLIN) within MATLAB and ANSYS can be used to accurately predict a unique set of elastic and visco-plastic properties of the composite constituents (Fig. 22). Convergence between numerical and experimental load displacement curves on composite constituents affected by environmental fatigue resulted in material properties listed in Table 9 and Table 10. It was found that, subjecting test coupons to the fatigue loads in air does not result in a significant change in the contact modulus of composite constituents,

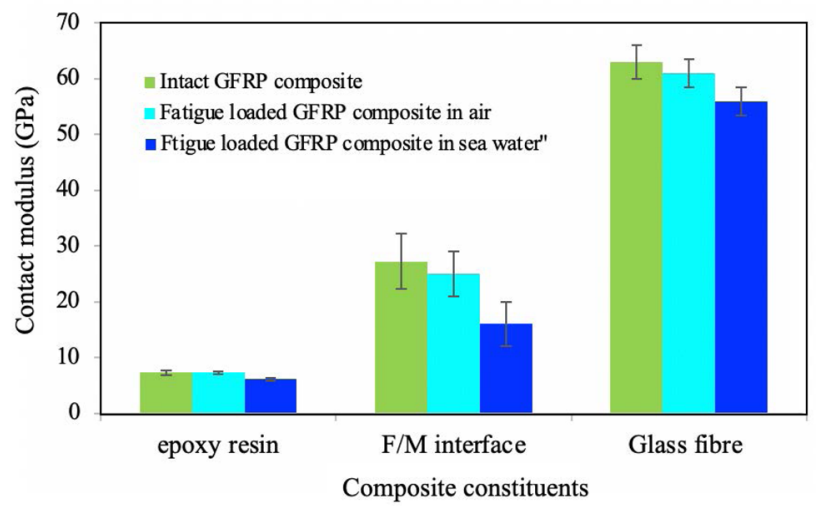

Fig. 23 Effect of environmental fatigue tests on the contact modulus of composite constituents 
Fig. 24 SEM micrograph showing the fiber surface of a sample failed by cyclic loading in (a) air and (b) in sea water (a)

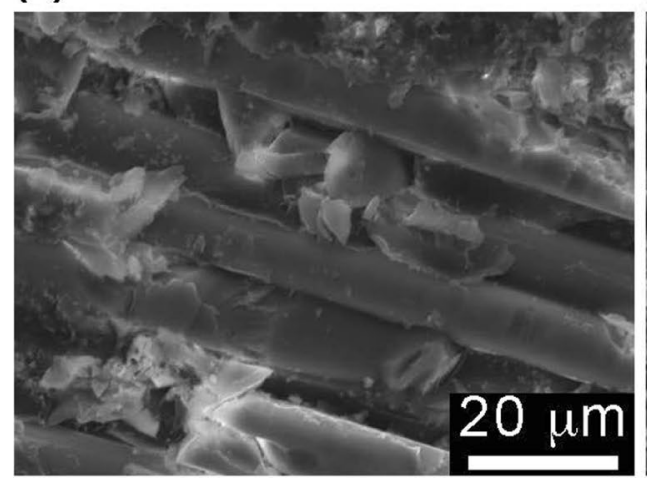

(b)

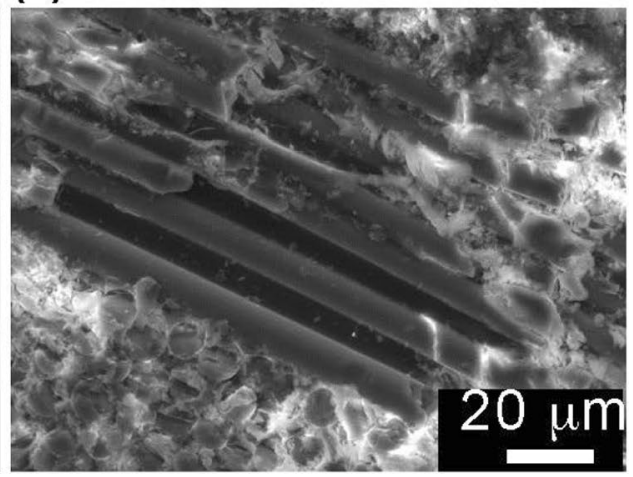

however, when test coupons are subjected to fatigue loads in sea water, the contact modulus of in situ epoxy resin, glass fibre and the F/M interface experience 11\%, $16 \%$ and $42 \%$ reduction respectively. The degradation of composite constituents due to the environmental effect of fatigue loading is shown in Fig. 23.

\section{Environmentally affected fatigue failure mechanisms}

The controlling effect of fiber/matrix interface regions on the environmentally affected fatigue performance of GFRP materials used in the design of tidal turbine blades was investigated in previous studies [24, 26]. In these studies, it was shown that while the main fatigue failure modes of composite materials tested in the air environment are; resin cracking, delamination, interfacial de-bonding between fibre and matrix and fibre breakage, the main fatigue failure mode when composite materials are tested in sea water is the degradation of the F/M interface. The SEM examination of the fatigue failed GFRP samples revealed that, for specimens tested in air, more matrix residue was attached to the fiber surface after failure. The relatively rough surface of fibers can be seen in Fig. 24(a), while "smoother" fiber surfaces with less matrix residue are observed on samples failed in an environmentally affected fatigue test (Fig. 24(b)). The difference on the fiber surface shows the destructive effect of fluid ingress on the bond between the fibers and the matrix. The process of environmentally affected fatigue involves combined degradation of interfaces with fibers and matrix cracking. Due to the crack initiation and propagation in the matrix which is due to cyclic mechanical stresses, access of sea water to the fiber surface accelerates the degradation process in the interphase regions by a mechanism of ionic exchange between the metallic cations at the glass fibre surface and the hydrogen ions in the sea water. This results in the extraction of sodium and potassium ions from the outer layer of the glass fiber. Fiber degradation in sea water is related to the removal of sodium and potassium ions from the fiber surface causing the development of surface micro pits, which act as stress raisers. This process subjects the glass fiber to the corrosion at an accelerated rate. The literature is abundant with similar findings and discussions when it comes to the environmentally affected fatigue behavior of polymer composites [43-52]. In addition, corrosive species such as chlorine (Fig. 25) attack the fiber surface reducing the mechanical properties of glass fibers [24]. In the present study, the nanoindentation test results from the failed specimens establish a strong causation for the strength decay of the F/M interface during cyclic testing in sea water.
Fig. 25 GFRP composite sample fatigued in seawater. (a) SEM image showing the location for EDX analysis; (b) EDX spectrum showing elements of chlorine not present in the samples tested in air (a)

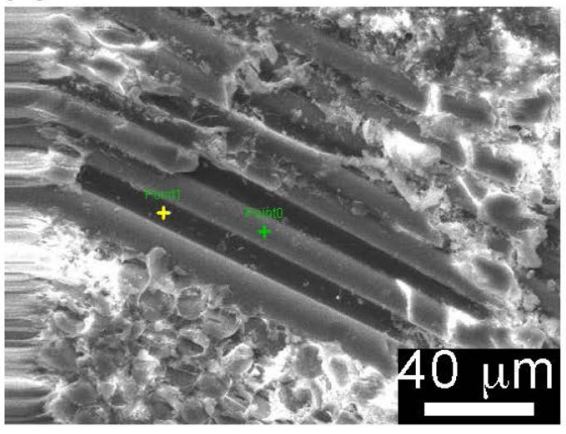

(b)

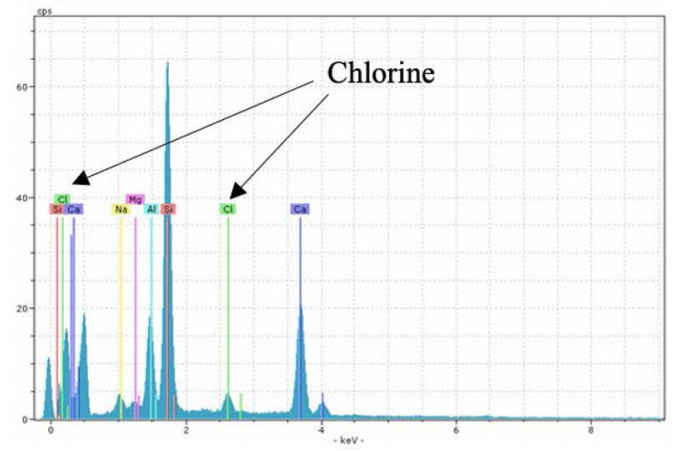




\section{Conclusion}

In this study, given the mechanical constraining effect of glass fibres, pile up and time dependent properties of the matrix phase, micromechanical characterization of the constituents of GFRP microstructure has been investigated numerically and experimentally using the nanoindentation method. Although, AFM images of residual indentation prints showed regions of material pile-up adjacent to the indentation, the large amount of viscoplastic recovery which occurs following indenter unloading makes the measurement of the mechanical response of the contact areas problematic. The use of FEM to determine the projected indentation contact area, given the viscoplasticity properties of the matrix phase, is shown to be useful when extracting the properties of the F/M interface and in situ resin properties by the nanoindentation method. In case of unreinforced epoxy resin, it was shown that the overestimation of the elastic modulus calculated by nanoindentation test method in relation to the macroscopic conventional test data (e.g. tensile tests) is mainly related to the effects of material pile up, viscoplasticity and hydrostatic stress. It was also found that, the FE calculated indentation modulus will be in a good agreement with macroscopic tensile modulus provided that the viscoplastic deformation is allowed to complete prior to unloading. FEM suggests that, this can be obtained by altering indentation settings (i.e. holding segment and/or strain rate), therefore the elastic modulus of bulk epoxy resin can be determined, independent of the viscous behaviour.

The developed 3D FE model with included fibre sections also shows the extent of stress transfer between the constituents depending on the location where the indentation test is conducted. In the case of indenting the matrix constituent, the FE model shows the stress transfer to the fibres and this occurs even at low indentation depth which one might assume would be free of the mechanical constraining effect of fibres, therefore the FE model developed in this work can be used to determine the indentation depth required to characterize the epoxy resin independent of the fibre constraining effect. A similar observation was made when indenting the glass fibre section where the indentation depth required to characterize the glass fibre properties independent of the effect of surrounding soft epoxy resin can be determined.

Finally, conducting nanoindentation testing on different parts of the composite microstructure of environmentally fatigue failed composite test coupons enabled a strong demonstration of the stiffness degradation of the $\mathrm{F} / \mathrm{M}$ interface regions. Therefore, it can be concluded that the macroscopic stiffness degradation of GFRP composite samples subjected to environmental fatigue loads studied in previous works is due to the stiffness degradation of individual composite constituents.
Acknowledgements We thank our colleagues from NRCEM projects who provided insight and expertise that greatly assisted the research.

Funding This research was supported by EPSRC through the NECEM (EP/R021503/1) project.

Data Availability The datasets generated during and/or analysed during the current study are available from the corresponding author on reasonable request.

\section{Declarations}

Ethics approval The work described has not been published before.

Consent to participate Each author has participated sufficiently in the work.

Consent for publication Not applicable.

Conflicts of interest On behalf of all authors, the corresponding author states that there is no conflict of interest.

Open Access This article is licensed under a Creative Commons Attribution 4.0 International License, which permits use, sharing, adaptation, distribution and reproduction in any medium or format, as long as you give appropriate credit to the original author(s) and the source, provide a link to the Creative Commons licence, and indicate if changes were made. The images or other third party material in this article are included in the article's Creative Commons licence, unless indicated otherwise in a credit line to the material. If material is not included in the article's Creative Commons licence and your intended use is not permitted by statutory regulation or exceeds the permitted use, you will need to obtain permission directly from the copyright holder. To view a copy of this licence, visit http://creativecommons.org/licenses/by/4.0/.

\section{References}

1. Gonabadi $\mathrm{H}$ et al (2021) Structural performance of composite tidal turbine blades. Compos Struct 278:114679

2. Gonabadi $\mathrm{H}$ et al (2021) Investigation of anisotropy effects in glass fibre reinforced polymer composites on tensile and shear properties using full field strain measurement and finite element multiscale techniques. J Compos Mater. https://doi.org/10.1177/ 00219983211054232

3. Hu Z, Farahikia M, Delfanian F (2015) Fiber bias effect on characterization of carbon fiber-reinforced polymer composites by nanoindentation testing and modeling. J Compos Mater 49(27):3359-3372

4. Rodríguez J et al (2006) Determination of mechanical properties of aluminium matrix composites constituents. Mater Sci Eng, A 437(2):406-412

5. Gregory JR, Spearing S (2005) Nanoindentation of neat and in situ polymers in polymer-matrix composites. Compos Sci Technol 65(3-4):595-607

6. Lee $\mathrm{S}-\mathrm{H}$ et al (2007) Evaluation of interphase properties in a cellulose fiber-reinforced polypropylene composite by nanoindentation and finite element analysis. Compos A Appl Sci Manuf 38(6):1517-1524

7. Hardiman M, Vaughan T, McCarthy C (2012) The effect of fibre constraint in the nanoindentation of fibrous composite microstructures: a finite element investigation. Comput Mater Sci 64:162-167 
8. Duan P et al (2018) Finite element modeling of nanoindentation response of elastic fiber-matrix composites. J Mater Res 33(17):2494-2503

9. VanLandingham M et al (1999) Characterization of nanoscale property variations in polymer composite systems: 1 . Experimental results. Compos Part A: appl sci manufacturing 30(1):75-83

10. Bogetti $\mathrm{T}$ et al (1999) Characterization of nanoscale property variations in polymer composite systems: 2 . Numerical modeling. Compos Part A: appl sci manufacturing 30(1):85-94

11. Vaughan T, McCarthy $C$ (2011) Micromechanical modelling of the transverse damage behaviour in fibre reinforced composites. Compos Sci Technol 71(3):388-396

12. Totry E, González C, LLorca J (2008) Failure locus of fiber-reinforced composites under transverse compression and out-of-plane shear. Comp Sci Technol 68(3-4):829-839

13. LLorca J et al (2011) Multiscale modeling of composite materials: a roadmap towards virtual testing. Adv maters 23(44):5130-5147

14. Gao S-L, Mäder E (2002) Characterisation of interphase nanoscale property variations in glass fibre reinforced polypropylene and epoxy resin composites. Compos A Appl Sci Manuf 33(4):559-576

15. Oliver WC, Pharr GM (1992) An improved technique for determining hardness and elastic modulus using load and displacement sensing indentation experiments. J Mater Res 7(6):1564-1583

16. Wang $\mathrm{Y}$ et al (2004) Orientation dependence of nanoindentation pile-up patterns and of nanoindentation microtextures in copper single crystals. Acta Mater 52(8):2229-2238

17. Cheng Y-T, Cheng C-M (2004) Scaling, dimensional analysis, and indentation measurements. Mater Sci Eng R Rep 44(4-5):91-149

18. Elmustafa A (2007) Pile-up/sink-in of rate-sensitive nanoindentation creeping solids. Modell Simul Mater Sci Eng 15(7):823

19. Garrido-Maneiro MÁ, Rodríguez J (2007) Nanoindentation by Multiple Loads Methodology: A Pile Up Correction Procedure in Key Engineering Materials. Trans Tech Publ

20. Bolshakov A, Pharr G (1998) Influences of pileup on the measurement of mechanical properties by load and depth sensing indentation techniques. J Mater Res 13(4):1049-1058

21. Gibson RF (2014) A review of recent research on nanoindentation of polymer composites and their constituents. Compos Sci Technol 105:51-65

22. Hardiman M, Vaughan T, McCarthy C (2015) Fibrous composite matrix characterisation using nanoindentation: The effect of fibre constraint and the evolution from bulk to in-situ matrix properties. Compos A Appl Sci Manuf 68:296-303

23. Hardiman M, Vaughan TJ, McCarthy CT (2016) The effects of pile-up, viscoelasticity and hydrostatic stress on polymer matrix nanoindentation. Polym Testing 52:157-166

24. Izadi Gonabadi H (2019) Performance of low cost composites for tidal turbine applications. Newcastle University

25. Gibhardt D et al (2019) Effects of hygrothermal ageing on the interphase, fatigue, and mechanical properties of glass fibre reinforced epoxy. Fibers 7(6):55

26. Gonabadi $\mathrm{H}$ et al (2021) Fatigue damage analysis of GFRP composites using digital image correlation. Journal of Ocean Engineering and Marine Energy 7(1):25-40

27. Iso BS (2003) 13003. Fibre-reinforced plastics-determination of fatigue properties under cyclic loading conditions. British Standards International

28. Sneddon IN (1965) The relation between load and penetration in the axisymmetric Boussinesq problem for a punch of arbitrary profile. Int J Eng Sci 3(1):47-57

29. VanLandingham MR (2003) Review of instrumented indentation. J Res Nat Inst Stand Technol 108(4):249

30. Nečas D, Klapetek P (2012) Gwyddion: an open-source software for SPM data analysis. Open Physics 10(1):181-188
31. Perzyna P (1966) Fundamental problems in viscoplasticity. Advances in applied mechanics. Elsevier, pp 243-377

32. Perzyna P (1936) The constitutive equation for work-hardening and rate sensitive plastic materials. in Proc. Vibrational Problems

33. Perzyna $P$ (1963) The constitutive equations for rate sensitive plastic materials. Q Appl Math 20(4):321-332

34. Marteau J, Bouvier S, Bigerelle M (2015) Review on numerical modeling of instrumented indentation tests for elastoplastic material behavior identification. Archives of Computational Methods in Engineering 22(4):577-593

35. Johnson KL, KL Johnson (1987) Contact mechanics 1987: Cambridge university press

36. Mata M, Alcala J (2004) The role of friction on sharp indentation. J Mech Phys Solids 52(1):145-165

37. Zhou $X$ et al (2008) Investigation on methods for dealing with pile-up errors in evaluating the mechanical properties of thin metal films at sub-micron scale on hard substrates by nanoindentation technique. Mater Sci Eng, A 488(1-2):318-332

38. Beegan D, Chowdhury S, Laugier M (2003) A nanoindentation study of copper films on oxidised silicon substrates. Surf Coat Technol 176(1):124-130

39. Saha R, Nix W (2001) Soft films on hard substrates - nanoindentation of tungsten films on sapphire substrates. Mater Sci Eng, A 319:898-901

40. Kese K, Li Z-C (2006) Semi-ellipse method for accounting for the pile-up contact area during nanoindentation with the Berkovich indenter. Scripta Mater 55(8):699-702

41. Cao Y et al (2006) Nanoindentation measurements of the mechanical properties of polycrystalline Au and Ag thin films on silicon substrates: Effects of grain size and film thickness. Mater Sci Eng, A 427(1-2):232-240

42. Rodríguez M et al (2012) Determination of the mechanical properties of amorphous materials through instrumented nanoindentation. Acta Mater 60(9):3953-3964

43. Carswell W, Roberts R (1980) Environmental fatigue stress failure mechanism for glass fibre mat reinforced polyester. Composites 11(2):95-99

44. Hofer $\mathrm{K}$ et al (1987) Effect of moisture on fatigue and residual strength losses for various composites. J Reinf Plast Compos 6(1):53-65

45. Schmitz G, Metcalfe A (1966) Stress corrosion of E-glass fibers. Ind Eng Chem Prod Res Dev 5(1):1-8

46. Metcalfe A, Schmitz G (1972) Mechanism of stress-corrosion in e glass filaments. Glass Technol 13(1):5-000

47. Komai K, Minoshima K, Shiroshita S (1991) Hygrothermal degradation and fracture process of advanced fibre-reinforced plastics. Mater Sci Eng, A 143(1-2):155-166

48. Pritchard G, Taneja N (1973) Water damage in polyester/ glass laminates. Part II: Microscopic evidence Composites 4(5):199-202

49. Fried N (1970) Degradation of composite materials: the effect of water on glass-reinforced plastics. Mechanics of composite materials. Elsevier, pp 813-837

50. Tsai SW (1979) Composite Materials: Testing and Design (Fifth Conference). ASTM

51. Doremus R (1974) Static fatigue in glass. Recent Advances in Science and Technology of Materials. Springer, pp 203-206

52. Romanenkov I (1967) Dependence of the Mechanical Properties of GRPs on their water Absorption. Soviet Plastics 2:74-75

Publisher's Note Springer Nature remains neutral with regard to jurisdictional claims in published maps and institutional affiliations. 